\title{
Transethosomal gels as carriers for the transdermal delivery of colchicine: statistical optimization, characterization, and ex vivo evaluation
}

This article was published in the following Dove Press journal: Drug Design, Development and Therapy

\author{
Ibrahim M Abdulbaqi \\ Yusrida Darwis \\ Reem Abou Assi \\ Nurzalina Abdul Karim \\ Khan
}

School of Pharmaceutical Sciences, Universiti Sains Malaysia, Minden, Penang, Malaysia
Correspondence: Yusrida Darwis School of Pharmaceutical Sciences,

Penang, Malaysia

Tel +6046534588

Fax +6046570017

Email yusrida@usm.my Universiti Sains Malaysia, I 1800 Minden,

\begin{abstract}
Introduction: Colchicine is used for the treatment of gout, pseudo-gout, familial Mediterranean fever, and many other illnesses. Its oral administration is associated with poor bioavailability and severe gastrointestinal side effects. The drug is also known to have a low therapeutic index. Thus to overcome these drawbacks, the transdermal delivery of colchicine was investigated using transethosomal gels as potential carriers.
\end{abstract}

Methods: Colchicine-loaded transethosomes (TEs) were prepared by the cold method and statistically optimized using three sets of $2^{4}$ factorial design experiments. The optimized formulations were incorporated into Carbopol $940^{\circledR}$ gel base. The prepared colchicine-loaded transethosomal gels were further characterized for vesicular size, dispersity, zeta potential, drug content, $\mathrm{pH}$, viscosity, yield, rheological behavior, and ex vivo skin permeation through Sprague Dawley rats' back skin.

Results: The results showed that the colchicine-loaded TEs had aspherical irregular shape, nanometric size range, and high entrapment efficiency. All the formulated gels exhibited non-Newtonian plastic flow without thixotropy. Colchicine-loaded transethosomal gels were able to significantly enhance the skin permeation parameters of the drug in comparison to the non-ethosomal gel.

Conclusion: These findings suggested that the transethosomal gels are promising carriers for the transdermal delivery of colchicine, providing an alternative route for drug administration. Keywords: transethosomes, ethosomal nanocarriers, colchicine, factorial design, skin permeation, rheology

\section{Introduction}

Colchicine is a potent alkaloid obtained from the dried corns and seeds of plants of the genus Colchicum, which belong to Liliaceae family. It has been used for the treatment of acute gout for $>2,000$ years. It is highly effective especially when given in the first $12-36$ hours of the gouty attack. ${ }^{1}$ Also, colchicine is the only available drug for treating familial Mediterranean fever (FMF). ${ }^{2}$ It has been reported to improve height development and weight parameters in children with FMF. ${ }^{3}$ A daily lifelong administration of colchicine is required to prevent both the fever/pain attacks and the silent amyloid deposition. ${ }^{4}$ Although colchicine tablets have been prescribed in the United States since the 19th century, it was only in 2009, the US Food and Drug Administration (FDA) approved colchicine for the treatment of acute gout and FMF. ${ }^{5}$

Colchicine is known to have low therapeutic index ${ }^{1,6}$ and poor oral bioavailability $(25 \%-50 \%)$ due to the extensive first-pass metabolism. ${ }^{7}$ In addition, the oral administration of colchicine is associated with mild to severe gastrointestinal side effects, including abdominal cramps and pain, nausea, vomiting, and diarrhea. ${ }^{8}$ These side 
effects commonly occur in around $80 \%$ of patients even at therapeutic doses. ${ }^{9,10}$ Alternatively, colchicine was administered intravenously, but this route of administration was associated with serious adverse effects such as tissue necrosis cytopenias, disseminated intravascular coagulation, and even death. ${ }^{8,11}$ The intravenous administration was banned by the FDA in 2008..$^{5}$ Thus, the use of colchicine has been limited due to all these drawbacks and adverse effects.

The transdermal delivery may offer a new route for the administration of colchicine to solve the problems of dosedependent side effects and the poor bioavailability associated with its oral administration. Based on literature search, it has been found that only two studies have reported the transdermal delivery of colchicine using lipid-based vesicular systems. In both the studies, elastic liposomes have been used. In the first study, colchicine alone was encapsulated in these vesicles. The authors found that the vesicular size, entrapment efficiency (EE\%), and the in vitro transdermal flux $\left(\mathrm{J}_{\mathrm{ss}}\right)$ values through abdominal rat skin were $135 \pm 11 \mathrm{~nm}$, $66.3 \% \pm 2.2 \%$, and $44.4 \pm 1.9 \mu \mathrm{g} / \mathrm{cm}^{2} / \mathrm{h}$, respectively. In the second study, in an attempt to enhance the $\mathrm{EE} \%$ and dermal deposition values and to prevent drug leakage upon storage, colchicine was complexed with $\beta$ cyclodextrin, and the complex was then entrapped in elastic liposomes. Although, EE\% was improved (79.5\% $1.6 \%)$, this was associated with a significant decrease in the flux $\left(26.4 \pm 1.2 \mu \mathrm{g} / \mathrm{cm}^{2} / \mathrm{h}\right)$ and an increase in the vesicular size $(152 \pm 14 \mathrm{~nm}) .{ }^{12,13}$ Furthermore, no stability studies were reported for both the formulations. Stability study is important, because drug leakage from elastic liposomal vesicles commonly occurs during storage, especially when a hydrophilic drug like colchicine is incorporated. ${ }^{13-15}$

Ethosomal nanocarriers are vesicular systems that contain a relatively high concentration of ethanol, in addition to phospholipids and water. They are specially designed for the dermal/transdermal delivery of therapeutic agents. Ethosomal systems are classified on the basis of their compositions into three classes: classical ethosomes, binary ethosomes, and transethosomes (TEs). ${ }^{16}$ TEs are the new generation of these nanocarriers; they were first developed in 2012. ${ }^{17}$ TEs contain the basic components of classical ethosomes and a penetration enhancer or an edge activator (surfactant) in their formula. The efficacy of TEs in enhancing the dermal and transdermal delivery of various therapeutic agents with different physicochemical properties has been proven by many researchers. ${ }^{17-20}$

The aim of the present study was to investigate the potential use of transethosomal gels as carriers for the transdermal delivery of colchicine as an alternative route for the drug administration. In this study, colchicine-loaded TEs were prepared and optimized statistically. The optimized formulations were incorporated into a gel base. Gels are the most suitable vehicles for the incorporation of ethosomal vesicles, because of their compatibility with these nanocarriers; and they provide the required viscosity and bioadhesive properties for the skin application. The prepared colchicine-loaded transethosomal gels were characterized in terms of vesicular size, dispersity $(Đ)$, zeta potential (ZP), $\mathrm{pH}$, drug content, and rheological properties. Ex vivo drug release studies were performed to determine and evaluate the skin permeation parameters. In addition, the stability of the optimized colchicine-loaded transethosomal gel was evaluated at different storage conditions.

\section{Materials and methods Materials}

Colchicine (purity $>97 \%$ ) was purchased from Acros Organics (Morris, NJ, USA). Phospholipon 90G ${ }^{\circledR}$ (PL90G) (contains $>90 \%$ phosphatidylcholine from soybean) was generously donated by Lipoid LLC (Newark, NJ, USA). Absolute ethanol (purity $\geq 99.5 \%$ ) was bought from Merck KGaA (Darmstadt, Germany). Tween $20^{\circledR}$ (purity $\geq 99 \%$ ), sodium stearate, and triethanolamine (purity $\geq 99 \%$ ) were purchased from R \& M Chemicals (Essex, UK). Sodium taurocholate, cholesterol, propyl paraben, methyl paraben, and Sephadex ${ }^{\circledR}$ G-25 were bought from Sigma-Aldrich Co., (St Louis, MO, USA). Propylene glycol (PG) and glacial acetic acid were obtained from QRëC (Selangor, Malaysia). Labrafil ${ }^{\circledR}$ M 1944 CS (Oleoyl macrogol-6 glycerides EP) was purchased from Gattefossé (Lyon, France). Carbopol $940^{\circledR}$ (cross-linked polyacrylate polymer) was a kind gift from Lubrizol Corporation (Wickliffe, OH, USA). Methanol and acetonitrile (high-performance liquid chromatography [HPLC] grade) were purchased from J.T. Baker (Phillipsburg, NJ, USA). Ammonium acetate was bought from Bendosen Laboratory Chemicals (Bendosen, Norway). Ultrapure water was prepared by Elga purelab classic UVF water purification system. All the other organic solvents and chemicals used were either of analytical or HPLC grades.

\section{Preparation of TEs}

Three different formulas of TEs were prepared using the cold method..$^{21}$ The organic phase was obtained by dissolving PL90G and surfactant (which is Tween $20^{\circledR}$, sodium taurocholate, or Labrafil ${ }^{\circledR}$ ) in ethanol at $30^{\circ} \mathrm{C}$. The aqueous phase (ultrapure water) was heated to $30^{\circ} \mathrm{C}$ and then added to the 
organic phase dropwise with continuous stirring at 1,200 rpm using a magnetic stirrer. The mixing continued for 45 minutes to get the transethosomal dispersions that were further subjected to a size-reduction process by multiple extrusions through a $200 \mathrm{~nm}$ pore size membrane using Acrodisc ${ }^{\circledR}$ syringe filters (PALL Life Sciences, Port Washington, NY, USA).

\section{Effects of formulation variables on the transethosomal properties}

Three sets of $2^{4}$ factorial design experiments were applied to study the effects of formulation variables on the transethosomal properties. Three different types of surfactants, namely Tween $20^{\circledR}$, sodium taurocholate, and Labrafil ${ }^{\circledR}$ were used in the study (Table 1). The full factorial design allows the quantification of the effects produced by the tested independent variables on the dependent variables such as the average vesicular size, $Ð$, and $\mathrm{ZP}$ and also shows the possible interactions between them.

The obtained results were analyzed using a Design-Expert ${ }^{\circledR}$ software, version 9.0.20 (Stat-Ease, Inc., Minneapolis, MN, USA). The significance of the individual independent variables and their possible interactions were evaluated using analysis of variance (ANOVA). Then, coded equations for identifying the relative impact of every factor were generated by comparing the coefficients of the factors using the software. Finally, 3D surface plots were used to visually explain the significant interactions between the independent variables and their effects on the studied responses.

\section{Vesicular size, $\bigoplus$, and ZP measurements}

The mean vesicular size and $\emptyset$ for various formulations were determined by photon correlation spectroscopy. The measurements were carried out using a Zetasizer 1000HSA (Malvern Instruments, Malvern, UK) at a fixed angle of $90^{\circ}$ and a wavelength of $633 \mathrm{~nm}$ at $25^{\circ} \mathrm{C} \pm 2^{\circ} \mathrm{C}$. Before measurements, the

Table I Factorial designs for the preparation of transethosomes

\begin{tabular}{lll}
\hline & \multicolumn{1}{l}{ Values } \\
\cline { 2 - 3 } & Low & High \\
\hline Independent variables & & \\
A. Ethanol concentration & $20 \% \mathrm{w} / \mathrm{w}$ & $35 \% \mathrm{w} / \mathrm{w}$ \\
B. PL90G concentration & $2 \% \mathrm{w} / \mathrm{w}$ & $4 \% \mathrm{w} / \mathrm{w}$ \\
C. Surfactant concentration* & $0.2 \% \mathrm{w} / \mathrm{w}$ & $0.4 \% \mathrm{w} / \mathrm{w}$ \\
D. Number of extrusions & 10 times & 20 times \\
Dependent variables & & \\
The average vesicular size $(\mathrm{nm})$ & & \\
Dispersity & & \\
Zeta potential $(\mathrm{mV})$ & & \\
\hline
\end{tabular}

Note: *Three surfactants Tween $20^{\circledR}$, sodium taurocholate, and Labrafi ${ }^{\circledR}$ were used separately in each factorial experiment.

Abbreviation: PL90G, Phospholipon 90G ${ }^{\circledR}$. samples were diluted with distilled water to obtain a suitable scattering intensity within the range of 100-150 kilocounts per second. The zeta potential of the various formulations was measured using a Zetasizer nanoseries Nano-Z (Malvern Instruments). Before measurement, the samples were also diluted with distilled water.

\section{Colchicine incorporation and optimization of EE\%}

TEs from all sets of designs with vesicular size $\leq 150 \mathrm{~nm}$, $Đ \leq 0.3$, and $\mathrm{ZP} \geq-20 \mathrm{mV}$ were chosen for further study. The selected TEs were loaded with a starting concentration of $0.2 \% \mathrm{w} / \mathrm{w}$ of colchicine. The incorporation of colchicine was done by dissolving the drug in the aqueous phase during the preparation process of the ethosomal systems. The drug-loaded TEs were then characterized for the vesicular size, $D, Z P$, and EE\%. Formulations that showed EE\% of colchicine $\geq 75 \%$ were selected for further optimization steps of the EE\%. Accordingly, the chosen formulations were further loaded with colchicine at concentrations of 0.3 and $0.5 \% \mathrm{w} / \mathrm{w}$, respectively, and evaluated for the vesicular size, $Ð, \mathrm{ZP}$, and $\mathrm{EE} \%$.

\section{Separation of the free colchicine and determination of $\mathrm{EE} \%$}

Sephadex G-25 minicolumn centrifugation technique was used to separate the colchicine-loaded TEs from the free (unentrapped) colchicine. ${ }^{22,23}$ The minicolumn was prepared by weighing $1 \mathrm{~g}$ of the sephadex beads which were then allowed to swell overnight in $6 \mathrm{~mL}$ of distilled water at room temperature. Then, the supernatant was decanted, and the swollen suspension was degassed in an ultrasonic bath (Branson 5510; Emerson Electric Co., St Louis, MO, USA) for 10 minutes and subsequently poured into a pre-prepared $3 \mathrm{~mL}$ syringe plugged with glass wool. The minicolumn was packed by centrifugation at 1,000 rpm for 2 minutes by using a Centrifuge 5702R (Eppendorf, Hamburg, Germany). Colchicine-loaded TEs $(1 \mathrm{~mL})$ were placed on the top of the column and centrifuged at 1,000 rpm for 2 minutes. Eluent containing colchicine-loaded TEs was collected and the free colchicine was retained in the column by size exclusion chromatographic method. The procedure was repeated twice by adding $1 \mathrm{~mL}$ of distilled water on the top of the column each time to assist the elution of colchicine-loaded TEs. All the eluents were collected and kept for further analysis. Then, $100 \mu \mathrm{L}$ of the eluent was dissolved in $5 \mathrm{~mL}$ of acetonitrile to lyse the vesicles and release the entrapped drug. The drug content was determined by a previously developed and validated 
HPLC method. ${ }^{24}$ The analyses were carried out with a liquid chromatography device (Shimadzu, Kyoto, Japan). The separation was done using a Hypersil Gold C-18 column $(250 \mathrm{~mm} \times 4.6 \mathrm{~mm}$ ID $\times 5 \mu \mathrm{m}$; Thermo Fisher Scientific, Waltham, MA, USA), and the column was maintained at $30^{\circ} \mathrm{C}$. The mobile phase consisted of acetonitrile:ammonium acetate buffer $(20 \mathrm{mmol} / \mathrm{L}, \mathrm{pH}=4.85 ; 32: 68 \mathrm{v} / \mathrm{v})$. The flow rate was set at $1 \mathrm{~mL} / \mathrm{min}$ while the sample injection volume was $10 \mu \mathrm{L}$. The detection wavelength was $353 \mathrm{~nm}$.

The EE\% was calculated using the following equation:

$$
\mathrm{EE} \%=\frac{\text { Weight of encapsulated colchicine }}{\text { Initial weight of colchicine }} \times 100
$$

\section{Preparation of the colchicine-loaded transethosomal gels}

Colchicine-loaded transethosomal gel was formed by incorporating the required amount of the optimized colchicineloaded TEs in a pre-prepared gel base at the ratio of 4:1 with gentle stirring, followed by manual mixing for 10 minutes. The gel base was prepared by dispersing Carbopol $940^{\circledR}$ $(2 \% \mathrm{w} / \mathrm{w})$ in distilled water and leaving to swell overnight in the refrigerator. Subsequently, methyl paraben and propyl paraben were dissolved in PG and then added to the gel mixture. The gel was then neutralized by the dropwise addition of triethanolamine with continuous manual mixing until $\mathrm{pH}$ value of 7.0 was reached, to get the final homogeneous transparent gel base. The composition of the gel base is summarized in Table 2. The non-ethosomal (NE) colchicine gel was prepared by dissolving colchicine in hydroethanolic solution $(35 \% \mathrm{w} / \mathrm{w})$ and then mixing with the gel base using the same ratio and procedure. The final colchicine concentration in all the prepared gels was $0.24 \% \mathrm{w} / \mathrm{w}$.

\section{Characterization of the colchicine-loaded transethosomal gels \\ Determination of $\mathrm{pH}$}

The $\mathrm{pH}$ of various gels was determined using a digital pH meter (HI-2213 bench pH Meter; Hanna Instruments,

Table 2 Composition of the gel base

\begin{tabular}{ll}
\hline Ingredients & Concentration \\
\hline Carbopol $940^{\circledR}$ & $2 \% \mathrm{w} / \mathrm{w}$ \\
Methyl paraben & $0.02 \% \mathrm{w} / \mathrm{w}$ \\
Propyl paraben & $0.01 \% \mathrm{w} / \mathrm{w}$ \\
Propylene glycol & $1 \% \mathrm{w} / \mathrm{w}$ \\
Distilled water & Up to $100 \% \mathrm{w} / \mathrm{w}$ \\
\hline
\end{tabular}

Woonsocket, RI, USA). Approximately $0.5 \mathrm{~g}$ of various transethosomal gels was dispersed in $20 \mathrm{~mL}$ of distilled water and stirred for 30 minutes using a magnetic stirrer at room temperature; the $\mathrm{pH}$ sensor probe electrode was then immersed into the dispersed gel, and the $\mathrm{pH}$ of the formulation was read from the digital display.

\section{Vesicular size, $\oplus$, and ZP of the incorporated TEs}

Mean size, $Ð$, and ZP were measured for the colchicineloaded transethosomal vesicles after their incorporation in the gel base. Colchicine-loaded gels were dispersed in $20 \mathrm{~mL}$ of distilled water and stirred for 30 minutes using a magnetic stirrer at room temperature. The samples were then diluted with distilled water, and the mean vesicular size, $Ð$, and $\mathrm{ZP}$ values were measured according to the methods described above.

\section{Rheological behavior, viscosity, and yield} measurements

The rheological properties of the colchicine-loaded transethosomal gels were evaluated using a Viscotech ${ }^{\circledR}$ rheometer (Rheologica Instruments AB, Lund, Sweden) equipped with a cone (C40-4) and plate measuring system. About $1 \mathrm{~g}$ of the gel sample was carefully placed on the plate to ensure that a correct gap-fill was obtained. The gap distance was set at $1 \mathrm{~mm}$. After bringing down the cone, the sample was left to equilibrate at $25^{\circ} \mathrm{C}$ for 25 seconds. A shear stress for the ascending flow curve was applied at 1-200 Pa while for the descending flow curve it was at 200-1 $\mathrm{Pa}$ in a linear pattern, and the rate measurements were recorded. A fresh gel sample was used for each run. The shear rate versus shear stress data were fitted to rheological models. The gel formulations showed non-Newtonian plastic flow and fitted the Bingham model of rheological behavior. Accordingly, the rheological parameters were calculated based on the following equation:

$$
\log G=N \log (S-F)-\log \eta
$$

where $\mathrm{G}$ is the shear rate in second ${ }^{-1}, \mathrm{~S}$ is the shear stress in Pascal, $F$ is the yield value, $\eta$ is the viscosity, and $N$ is the slope of $\log (\mathrm{S}-\mathrm{F})$ against $\log \mathrm{G}$ plot. When $\mathrm{N}$ is 1 , plastic flow with the Bingham model is indicated. ${ }^{25}$

\section{Ex vivo skin permeation studies}

The ex vivo skin permeation studies were carried out using the skin of male Sprague Dawley rats at the age of 
6-7 weeks and weighing $\sim 180-200 \mathrm{~g}$. The study was conducted according to the Universiti Sains Malaysia guidelines for the care and use of animals for scientific purposes. The experimental protocol was approved by the Animal Ethics Committee of Universiti Sains Malaysia (USM/Animal Ethics Approval/2014 (91) (572)). The rats were obtained from the animal house of the university.

\section{Preparation of the skin}

Rats were sacrificed using an overdose of carbon dioxide $\left(\mathrm{CO}_{2}\right)$ gas. The hair on the dorsal side of the animal was carefully removed using an electrical hair clipper. The shaven part of the skin (full thickness) was excised from the animal, and the subcutaneous fat tissue was carefully removed. Subsequently, the excised skin was washed thoroughly with phosphate-buffered saline (PBS, $\mathrm{pH}=6.4$ ) and examined visually for integrity or any cracks or furrows, and then sliced into sections and used for permeation studies.

\section{Skin permeation studies}

The ex vivo skin permeation experiments were carried out to determine and compare the skin permeation parameters between the optimized transethosomal gels and the NE gel formula. All the gels contained the same concentration of colchicine $(0.24 \% \mathrm{w} / \mathrm{w})$. The experiments were performed using standard $9 \mathrm{~mm}$ jacketed clear glass static Franz diffusion cells (V3 3-Station vertical cell stirrer; PermeGear Inc., Hellertown, PA, USA). The Franz diffusion cell was composed of two compartments; the donor and the receptor compartments. The effective diffusion area was $0.636 \mathrm{~cm}^{2}$ and the volume of the receptor compartment was $5 \mathrm{~mL}$. Prior to permeation experiments, a piece of back skin of rat was mounted between the donor and the receptor compartments while keeping the stratum corneum side of the skin facing toward the donor compartment. The receptor compartment was filled with PBS ( $\mathrm{pH}=6.4$ ), stirred at $500 \mathrm{rpm}$, and the temperature was maintained at $37.0^{\circ} \mathrm{C} \pm 0.1^{\circ} \mathrm{C}$. After equilibration for 30 minutes, $1 \mathrm{~g}$ of each gel formulation was placed in the donor compartment. At predetermined time intervals of $1,2,4,6,8,12$, and 24 hours, a volume of $0.5 \mathrm{~mL}$ was withdrawn from the receptor nozzle and immediately replaced with an equal volume of fresh medium (at the same temperature) to maintain the receptor phase volume at a constant level. The amounts of colchicine in the collected samples were quantified using the HPLC method described above.

\section{Data analysis of the skin permeation studies}

The cumulative amount of colchicine permeated through the rat skin $\left(Q_{f}\right)$ into the receptor medium was calculated using the following equation:

$$
\mathrm{Q}_{\mathrm{t}}=\left[\mathrm{C}_{\mathrm{t}} \mathrm{V}_{\mathrm{r}}+\sum_{\mathrm{i}=1}^{\mathrm{t}-1} \mathrm{C}_{\mathrm{i}} \mathrm{V}_{\mathrm{s}}\right]
$$

where $\mathrm{C}_{\mathrm{t}}$ is the concentration of colchicine $(\mu \mathrm{g} / \mathrm{mL})$ at each sampling interval, $\mathrm{V}_{\mathrm{r}}$ is the receptor volume of the individual Franz diffusion cell $(5 \mathrm{~mL}), \mathrm{C}_{\mathrm{i}}$ is the concentration of colchicine $(\mu \mathrm{g} / \mathrm{mL})$ at the $i$ th sample, and $\mathrm{V}_{\mathrm{s}}$ is the sampling volume $(0.5 \mathrm{~mL})$. The data were expressed as the cumulative amount of colchicine per unit area of the rat skin, $Q_{t} / A$ $\left(\mathrm{A}=0.636 \mathrm{~cm}^{2}\right){ }^{26}$

For the calculation of the permeation flux $\left(\mathrm{J}_{\mathrm{ss}}\right)$, the cumulative amount of colchicine from various colchicine-loaded gels permeated per unit area through the rat skin was plotted against time ( $t)$. The slope and intercept of the linear portion of the plots were derived by regression, and the flux was calculated as the slope divided by the skin surface area (Equation 4).

$$
\mathrm{J}_{\mathrm{sS}}=(\mathrm{dQ} / \mathrm{dt}) / \mathrm{A}
$$

where $J_{\text {ss }}$ is the steady state flux $\left(\mu \mathrm{g} / \mathrm{cm}^{2} / \mathrm{h}\right)$, A is the effective diffusion area of the skin through which the drug permeation takes place, and dQ/dt is the amount of drug passing through the skin per unit time at a steady-state $(\mu \mathrm{g} / \mathrm{h}){ }^{27}$

The permeability coefficient $(\mathrm{Kp}$, measured in $\mathrm{cm} / \mathrm{h}$ ) was calculated from the following equation:

$$
\mathrm{Kp}=\mathrm{J}_{\mathrm{ss}} / \mathrm{Cd}
$$

where $\mathrm{Cd}$ represents the drug concentration applied on the skin in the donor compartment. ${ }^{28}$

\section{Determination of the drug content in the optimized transethosomal gel}

The drug content in the optimized colchicine-loaded transethosomal gel was determined by weighing $0.5 \mathrm{~g}$ of the formula and then dispersing it in $20 \mathrm{~mL}$ of distilled water under continuous mixing with a magnetic stirrer for 60 minutes. The dispersion was then sonicated in an ultrasonic bath (Branson 5510) for 10 minutes. A suitable volume was removed and diluted with the mobile phase, and the drug content was measured using HPLC. 


\section{Transmission electron microscopy (TEM)}

TEM was used to study the morphology and for further verification of the vesicular size of the optimized colchicineloaded transethosomal formulation in its initial suspension form and in the gel formulation. The samples were visualized under a TEM (LIBRA 120; Carl Zeiss Meditec AG, Jena, Germany). For the colchicine-loaded transethosomal suspension, a fixed volume of the formulation was diluted 100-fold with distilled water, while for the colchicine-loaded transethosomal gel, $0.5 \mathrm{~g}$ of the gel was dispersed in $25 \mathrm{~mL}$ of distilled water and stirred for 60 minutes using a magnetic stirrer. A drop of either dispersion was placed onto a carboncoated copper grid, air dried, and then negatively stained with $2 \%$ phosphotungstic acid. The grid was allowed to dry in the air and then viewed under the TEM.

\section{Stability studies}

The stability studies of the final optimized colchicine-loaded transethosomal gel formulation were carried out by placing freshly prepared samples of the gel in two different storage conditions; namely refrigerated at $4{ }^{\circ} \mathrm{C} \pm 2^{\circ} \mathrm{C}$ and room temperature at $25^{\circ} \mathrm{C} \pm 2{ }^{\circ} \mathrm{C} / 60 \% \pm 5 \%$ relative humidity (RH) for 3 months. The prepared formulations were evaluated in terms of vesicular size, $Ð, \mathrm{ZP}, \mathrm{pH}$, drug content, viscosity, yield, and rheological behavior.

\section{Statistical analyses}

All experiments were repeated at least three times. The results obtained from the characterization, skin permeation, and stability studies of the various colchicine-loaded formulations were analysed statistically using one-way ANOVA and post hoc Tukey-honestly significant difference tests. All the statistical analyses were performed using a Minitab ${ }^{\circledR}$ statistical software, version 17.2.1.0 (Minitab, Inc., State College, PA, USA). Data are expressed as mean values with the standard deviation (mean $\pm \mathrm{SD}$ ), and a $P$-value $<0.05$ was considered statistically significant.

\section{Results and discussion Preparation and optimization of TEs}

The cold method was adopted for the preparation of TEs as it is simple and does not require highly specialized equipment or extreme conditions. Vesicular size is an important parameter that should be considered in the preparation of nanocarriers for transdermal drug delivery. It has been reported that the vesicular size should be $<200 \mathrm{~nm}$ to be suitable for this route of administration. ${ }^{29,30}$ Accordingly, the prepared vesicles were subjected to multiple extrusions through $200 \mathrm{~nm}$ pore size membrane, to produce smaller vesicular size. In the initial stage of the preparation, it was found that the vesicular size and $\oslash$ of all the prepared ethosomal systems before the multiple extrusion process were $>340 \mathrm{~nm}$ and $>0.2$, respectively. It was recommended in the literature that the number of extrusions should be either 10 or 20 times to get the required homogeneous dispersions. ${ }^{31-33}$ In order to study the effects of the number of extrusions on the vesicular properties, both the numbers of extrusions (ie, 10 and 20 times) were selected as the low and high levels and studied for all the formulations.

Ethanol is a major constituent of the ethosomal systems, giving them their unique characteristics. It is usually used at concentrations of $10 \%-50 \%$. However, at high ethanol concentrations and beyond certain levels, it may cause the vesicular bilayers of TEs to be leaky due to the partial solubilization of the lipid bilayers, which may lead to a significant decrease in $\mathrm{EE} \%$. Further increase in its concentration would lead to vesicle solubilization. Therefore, in the preliminary studies, ethanol concentration at higher levels $(30,35,40$, and $45 \% \mathrm{w} / \mathrm{w})$ was investigated. It was found that ethanol concentrations of $40 \% \mathrm{w} / \mathrm{w}$ caused the vesicular size to increase. This could be because the vesicular bilayers were partially solubilized (ie, sublysis stage). At higher ethanol concentration of $45 \% \mathrm{w} / \mathrm{w}$, a complete solubilization of the vesicles occurred, and the TEs no longer existed. Therefore, the highest level of ethanol concentration used in this study was fixed at $35 \% \mathrm{w} / \mathrm{w}$. The optimized lower level of ethanol concentration was selected at $20 \% \mathrm{w} / \mathrm{w}$, as it was found that at lower levels of ethanol concentrations (below 20\%w/w) the vesicular size was increased to more than the required limit of $200 \mathrm{~nm}$. This finding is in agreement with previous studies which showed that the vesicular size increased by decreasing ethanol concentration..$^{21,34}$

The commonly used phospholipid concentration in the preparation of ethosomal systems ranged between 0.5 and $5 \% \mathrm{w} / \mathrm{w} \cdot{ }^{35}$ In this study, the selected upper and lower levels of the phospholipid (PL90G) concentrations were 4 and $2 \% \mathrm{w} / \mathrm{w}$, respectively. It was observed that at concentrations $>4 \% \mathrm{w} / \mathrm{w}$, the size of the vesicles was $>200 \mathrm{~nm}$. Similar results for the size increment were obtained at concentrations $<2 \% \mathrm{w} / \mathrm{w}$, as the vesicle bilayers reach the sublysis concentration due to the presence of a relatively low concentration of lipid and very high concentration of ethanol. The vesicles at this stage become leaky, and hence lower EE\% is expected.

In the preliminary stage of the study, various types and concentrations $(0.05 \%-0.5 \% \mathrm{w} / \mathrm{w})$ of surfactants such as Tween $20^{\circledR}$, Labrafil ${ }^{\circledR}$ (nonionic surfactants), sodium taurocholate, sodium stearate (anionic surfactants), or vesicle 
stabilizers such as cholesterol were investigated. Tween $20^{\circledR}$, Labrafil $^{\circledR}$, and sodium taurocholate were found to produce homogeneous and stable vesicular dispersions within the concentration range of $0.2 \%-0.4 \% \mathrm{w} / \mathrm{w}$. In contrast, sodium stearate and cholesterol led to the formation of nonhomogeneous and unstable dispersions, and they were excluded from the study.

The composition of all formulations and the results of the studied responses of all the factorial design experiments are shown in Tables 3-5. Formulations with vesicular size $\leq 150 \mathrm{~nm}, \emptyset \leq 0.3$, and $\mathrm{ZP} \geq-20 \mathrm{mV}$ were bolded in the tables. These TEs were selected for further studies.

\section{Analysis of the full factorial designs}

The results of regression analysis of the size, $Ð$, and ZP responses of all the designs are summarized in Table 6. It was revealed that the produced models for the vesicular size, $Ð$, and $\mathrm{ZP}$ are significant $(p<0.05)$ with nonsignificant lack of fit for all the three conducted factorial experiments. To confirm that the proposed models can be used to navigate the design space, "adequate precision" values were calculated and were found to be $>4$ (the desirable value) in all responses and for all the factorial designs, indicating adequate signal to noise ratio. The predicted $R^{2}$ values were in a reasonable agreement with the adjusted $R^{2}$ values in all responses, except for the $Ð$ in transethosomes with sodium taurocholate (TENa) design,

Table 3 Experimental design and value of each factor and responses for transethosomes with Tween $20^{\circledR}$ (TET) design

\begin{tabular}{|c|c|c|c|c|c|c|c|}
\hline \multirow[t]{2}{*}{ Code } & \multicolumn{4}{|c|}{ Factors } & \multicolumn{3}{|l|}{ Responses } \\
\hline & A & B & C & D & Size & $\bigoplus$ & ZP $(m \mathbf{m})$ \\
\hline TET I & 20 & 2 & 0.2 & 10 & $145.6 \pm 3.5$ & $0.164 \pm 0.013$ & $-25.97 \pm 1.65$ \\
\hline TET 2 & 35 & 2 & 0.2 & 10 & $110.4 \pm 5.9$ & $0.167 \pm 0.043$ & $-26.13 \pm 0.40$ \\
\hline TET 3 & 20 & 4 & 0.2 & 10 & $152.0 \pm 3.2$ & $0.124 \pm 0.040$ & $-19.93 \pm 0.60$ \\
\hline TET 4 & 35 & 4 & 0.2 & 10 & $107.8 \pm 5.5$ & $0.143 \pm 0.023$ & $-20.93 \pm 0.82$ \\
\hline TET 5 & 20 & 2 & 0.4 & 10 & $129.6 \pm 2.3$ & $0.090 \pm 0.033$ & $-18.57 \pm 2.98$ \\
\hline TET 6 & 35 & 2 & 0.4 & 10 & $108.5 \pm 10.2$ & $0.120 \pm 0.022$ & $-26.63 \pm 0.74$ \\
\hline TET 7 & 20 & 4 & 0.4 & 10 & $133.7 \pm 12.7$ & $0.112 \pm 0.024$ & $-17.50 \pm 1.88$ \\
\hline TET 8 & 35 & 4 & 0.4 & 10 & $89.5 \pm 3.2$ & $0.145 \pm 0.025$ & $-22.00 \pm 0.94$ \\
\hline TET 9 & 20 & 2 & 0.2 & 20 & $\mid 42.4 \pm I .8$ & $0.154 \pm 0.007$ & $-25.67 \pm 1.60$ \\
\hline TET 10 & 35 & 2 & 0.2 & 20 & $103.6 \pm 3.4$ & $0.119 \pm 0.012$ & $-22.30 \pm 1.50$ \\
\hline TET I। & 20 & 4 & 0.2 & 20 & $146.3 \pm 3.7$ & $0.113 \pm 0.010$ & $-18.03 \pm 1.02$ \\
\hline TET 12 & 35 & 4 & 0.2 & 20 & $99.6 \pm 4.2$ & $0.138 \pm 0.041$ & $-19.03 \pm 1.58$ \\
\hline TET 13 & 20 & 2 & 0.4 & 20 & $125.2 \pm 2.3$ & $0.085 \pm 0.023$ & $-19.97 \pm 0.98$ \\
\hline TET I4 & 35 & 2 & 0.4 & 20 & $109.5 \pm 11.9$ & $0.086 \pm 0.036$ & $-23.40 \pm 1.15$ \\
\hline TET I5 & 20 & 4 & 0.4 & 20 & $127.7 \pm 8.6$ & $0.080 \pm 0.011$ & $-17.40 \pm 1.34$ \\
\hline TET I6 & 35 & 4 & 0.4 & 20 & $86.0 \pm 3.4$ & $0.150 \pm 0.028$ & $-19.10 \pm 1.85$ \\
\hline
\end{tabular}

Notes: Each value is expressed as mean \pm standard deviation $(n=3)$. A, ethanol concentration (\%w/w); B, PL90G concentration (\%w/w); C, Tween $20^{\circledR}$ concentration $(\% \mathrm{w} / \mathrm{w})$; $D$, number of extrusions. Formulations with vesicular size $\leq 150 \mathrm{~nm}, \Theta \leq 0.3$, and $Z P \geq-20 \mathrm{mV}$ are shown in bold.

Abbreviations: $\bigoplus$, dispersity; ZP, zeta potential; PL90G, Phospholipon 90G ${ }^{\circledR}$.
Table 4 Experimental design and value of each factor and responses for transethosomes with sodium taurocholate (TENa) design

\begin{tabular}{|c|c|c|c|c|c|c|c|}
\hline \multirow[t]{2}{*}{ Code } & \multicolumn{4}{|c|}{ Factors } & \multicolumn{3}{|l|}{ Responses } \\
\hline & A & B & C & D & ize $(\mathrm{nm})$ & $\boldsymbol{\theta}$ & $\mathrm{ZP}(\mathrm{mV})$ \\
\hline TENa I & 20 & 2 & 0.2 & 10 & $166.8 \pm 1.0$ & $0.160 \pm 0.014$ & $-24.87 \pm 2.39$ \\
\hline TENa 2 & 35 & 2 & 0.2 & 10 & $94.3 \pm 3.4$ & $0.131 \pm 0.013$ & $-31.30 \pm 3.90$ \\
\hline TENa 3 & 20 & 4 & 0.2 & 10 & $146.4 \pm 2.8$ & $0.092 \pm 0.04 I$ & $-26.37 \pm I .72$ \\
\hline TENa 4 & 35 & 4 & 0.2 & 10 & $90.6 \pm 3.1$ & $0.085 \pm 0.005$ & $-26.77 \pm 1.01$ \\
\hline TENa 5 & 20 & 2 & 0.4 & 10 & $159.3 \pm 7.5$ & $0.129 \pm 0.017$ & $-31.17 \pm 1.93$ \\
\hline TENa 6 & 35 & 2 & 0.4 & 10 & $97.4 \pm 3.6$ & $0.108 \pm 0.020$ & $-37.00 \pm 0.93$ \\
\hline TENa 7 & 20 & 4 & 0.4 & 10 & $127.3 \pm 2.7$ & $0.110 \pm 0.023$ & $-25.40 \pm 0.88$ \\
\hline TENa 8 & 35 & 4 & 0.4 & 10 & $94.2 \pm 2.1$ & $0.154 \pm 0.015$ & $-33.47 \pm 0.52$ \\
\hline TENa 9 & 20 & 2 & 0.2 & 20 & $158.0 \pm 8.7$ & $0.093 \pm 0.034$ & $-21.47 \pm 2.11$ \\
\hline TENa 10 & 35 & 2 & 0.2 & 20 & $85.8 \pm 1.9$ & $0.115 \pm 0.015$ & $-24.10 \pm 0.16$ \\
\hline TENa I I & 20 & 4 & 0.2 & 20 & $140.0 \pm 3.6$ & $0.110 \pm 0.004$ & $-22.63 \pm 0.42$ \\
\hline TENa I 2 & 35 & 4 & 0.2 & 20 & $85.4 \pm 5.4$ & $0.087 \pm 0.007$ & $-25.47 \pm 0.98$ \\
\hline TENa I3 & 20 & 2 & 0.4 & 20 & $152.6 \pm 9.2$ & $0.098 \pm 0.033$ & $-30.30 \pm 0.54$ \\
\hline TENa I4 & 35 & 2 & 0.4 & 20 & $92.4 \pm 3.8$ & $0.111 \pm 0.019$ & $-31 .|7 \pm 2.2|$ \\
\hline TENa I 5 & 20 & 4 & 0.4 & 20 & $128.8 \pm 3.3$ & $0.130 \pm 0.04 \mid$ & $-26.77 \pm 0.29$ \\
\hline TENa 16 & 35 & 4 & 0.4 & 20 & $88.9 \pm 3.9$ & $0.1 \mid 7 \pm 0.052$ & $-32.10 \pm 1.53$ \\
\hline
\end{tabular}

Notes: Each value is expressed as mean \pm standard deviation $(n=3)$. A, ethanol concentration (\%w/w); B, PL90G concentration (\%w/w); C, sodium taurocholate concentration (\%w/w); D, number of extrusions. Formulations with vesicular size $\leq 150 \mathrm{~nm}, \Theta \leq 0.3$, and $Z P \geq-20 \mathrm{mV}$ are shown in bold.

Abbreviations: $\oplus$, dispersity; ZP, zeta potential; PL90G, Phospholipon 90G ${ }^{\circledR}$.

which had a negative predicted $R^{2}$ value implying that the overall mean is a better predictor of the response. ${ }^{36}$

Coded equations (Table 7) for the studied responses (ie, vesicular size, $\oslash$, and ZP) were generated by the software

Table 5 Experimental design and value of each factor and responses for transethosomes with Labrafil ${ }^{\circledR}(T E L)$ design

\begin{tabular}{|c|c|c|c|c|c|c|c|}
\hline \multirow[t]{2}{*}{ Code } & \multicolumn{4}{|c|}{ Factors } & \multicolumn{3}{|l|}{ Responses } \\
\hline & A & B & c & D & ) & Ð & $P(\mathrm{mV})$ \\
\hline & 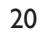 & 2 & - & . & & 08 & 48 \\
\hline EL 2 & 35 & 2 & 0.2 & 10 & & 0.006 & \pm 1.65 \\
\hline EL 3 & 20 & 4 & 0.2 & 10 & 1.5 & $0.183 \pm 0.011$ & $-17.37 \pm 1.20$ \\
\hline EL 4 & 35 & 4 & 0.2 & 10 & $4.3 \pm 2.6$ & $0.262 \pm 0.021$ & $-25.17 \pm 8.09$ \\
\hline EL 5 & 20 & 2 & 0.4 & 10 & & & \\
\hline EL 6 & 35 & 2 & 0.4 & 10 & 1.2 & 0.23 & \\
\hline EL 7 & 20 & 4 & 0.4 & 10 & & 0.1 & 7.30 \\
\hline & 35 & 4 & & 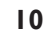 & & & \\
\hline L 9 & 20 & 2 & 0.2 & 20 & & & \\
\hline EL 10 & 35 & 2 & 0.2 & 20 & $94.5 \pm 2.9$ & $0.168 \pm 0.027$ & \pm 0.92 \\
\hline EL II & 20 & 4 & 0.2 & 20 & $159.1 \pm 0.6$ & $0.179 \pm 0.013$ & $-18.03 \pm 1.07$ \\
\hline 12 & 3 & 4 & 0.2 & 20 & & & \\
\hline TEL I 3 & 20 & 2 & 0.4 & 20 & $162.3 \pm 5.5$ & 0.18 & \pm 2.82 \\
\hline TEL 14 & 35 & 2 & 0.4 & 20 & $133.1 \pm 2.7$ & $0.150 \pm 0.008$ & $-10.58 \pm 3.44$ \\
\hline EL 15 & 20 & 4 & 0.4 & 20 & $149.2 \pm 1.7$ & $0.130 \pm 0.021$ & $-16.13 \pm 4.57$ \\
\hline EL 16 & 35 & 4 & 0.4 & 20 & $104.0 \pm 3.6$ & $0.154 \pm 0.033$ & $-12.93 \pm 1.92$ \\
\hline
\end{tabular}

Notes: Each value is expressed as mean \pm standard deviation $(n=3)$. A, ethanol concentration (\%w/w); B, PL90G concentration (\%w/w); C, Labrafi ${ }^{\circledast}$ concentration $(\% \mathrm{w} / \mathrm{w})$; D, number of extrusions. Formulations with vesicular size $\leq 150 \mathrm{~nm}, \oslash \leq 0.3$, and $Z P \geq-20 \mathrm{mV}$ are shown in bold.

Abbreviations: $\Theta$, dispersity; ZP, zeta potential; PL90G, Phospholipon 90G ${ }^{\circledR}$. 
Table 6 Results of regression analysis for the responses of the size, $\bigoplus$, and ZP for all the designs

\begin{tabular}{|c|c|c|c|c|c|c|}
\hline Design & Responses & $R^{2}$ & $\begin{array}{l}\text { Adjusted } \\
R^{2}\end{array}$ & $\begin{array}{l}\text { Predicted } \\
R^{2}\end{array}$ & $\begin{array}{l}\text { Adequate } \\
\text { precision }\end{array}$ & Significant factors \\
\hline TET & $\begin{array}{l}\text { Size }(\mathrm{nm}) \\
\bigoplus \\
\mathrm{ZP}(\mathrm{mV})\end{array}$ & $\begin{array}{l}0.9051 \\
0.4695 \\
0.8068\end{array}$ & $\begin{array}{l}0.8856 \\
0.3766 \\
0.76 I I\end{array}$ & $\begin{array}{l}0.8562 \\
0.236 \\
0.6918\end{array}$ & $\begin{array}{l}21.096 \\
7.007 \\
11.683\end{array}$ & $\begin{array}{l}A, C, D, A B, A C, B C \\
A, C, A B, B C \\
A, B, C, D, A C, A D, B C, A B C\end{array}$ \\
\hline TENa & $\begin{array}{l}\text { Size }(\mathrm{nm}) \\
\bigoplus \\
\mathrm{ZP}(\mathrm{mV})\end{array}$ & $\begin{array}{l}0.9721 \\
0.4258 \\
0.861\end{array}$ & $\begin{array}{l}0.9672 \\
0.2504 \\
0.8079\end{array}$ & $\begin{array}{l}0.9598 \\
-0.0207 \\
0.723\end{array}$ & $\begin{array}{l}35.389 \\
5.79 \\
14.922\end{array}$ & $\begin{array}{l}A, B, C, D, A B, A C \\
B C, A B D \\
A, B, C, D, B C, B D, A B C\end{array}$ \\
\hline TEL & $\begin{array}{l}\text { Size }(\mathrm{nm}) \\
\bigoplus \\
\mathrm{ZP}(\mathrm{mV})\end{array}$ & $\begin{array}{l}0.7858 \\
0.5751\end{array}$ & $\begin{array}{l}0.7204 \\
0.376\end{array}$ & $\begin{array}{l}0.6192 \\
0.0441\end{array}$ & $\begin{array}{l}12.784 \\
5.942\end{array}$ & $\begin{array}{l}A, B, C, D, A B, A C, A D, B C, B D, \\
C D, A B C, A B D, B C D, A B C D \\
A, B, D, A C, A D, B C \\
A, C, D, A B\end{array}$ \\
\hline
\end{tabular}

Note: A, B, C, and D refer to the independent variables selected for every factorial design experiment as illustrated in Table I.

Abbreviations: $\oplus$, dispersity; ZP, zeta potential; TET, transethosomes with Tween $20^{\circledR}$; TENa, transethosomes with sodium taurocholate; TEL, transethosomes with Labrafil ${ }^{\circledR}$.

to determine the magnitude of the effect of individual factors and the interactions between factors in all the designs. A positive value before a factor in the response equation denotes a positive impact (synergistic effect) that favors optimization, while a negative value indicates a negative impact (antagonistic effect) or inverse relation between the factor and the response. ${ }^{37}$ The $3 \mathrm{D}$ response surface plots are useful to understand the effect of interactions between the factors on single response (Figures 1-3). Only the statistically significant interactions $(p<0.05)$ were selected for these plots.

\section{Effects of formulation variables on the transethosomal properties}

For ease of understanding, the effects of individual factors on the vesicular size, $Ð$, and ZP of the prepared ethosomal systems in all the designs are summarized in Table 8.
Factors that had statistically significant effects $(p<0.05)$ on the responses are labeled with asterisks.

\section{Effects of formulation variables on the vesicular size and $\oplus$}

The vesicular size of ethosomal systems plays an important role in skin permeation. Smaller vesicular size $(<200 \mathrm{~nm})$ facilitates the TEs to pass through the small pores of the skin leading to more enhanced skin permeation. The size of all the prepared TEs was $<200 \mathrm{~nm}$ (ranging from 85.4 to $169.9 \mathrm{~nm}$ ) with low $Ð$ values (ranging from 0.08 to 0.262 ) as illustrated in Tables $3-5$. $Ð$ values $<0.3$ are considered ideal and indicate a narrow size distribution. ${ }^{38}$

It was observed that increasing ethanol concentration significantly reduced the vesicular size, but within the concentration range of $20 \%-35 \% \mathrm{w} / \mathrm{w}(p<0.05)$, as shown in $3 \mathrm{D}$ surface plots (Figures 1-3). Increasing ethanol concentration beyond

Table 7 Coded equations of the size, $\oplus$, and ZP for all the designs

\begin{tabular}{|c|c|c|c|}
\hline Design & Equations for vesicular size & Equations for $\boxplus$ & Equations for ZP \\
\hline TET & $\begin{array}{l}\text { Size }=+119.84-17.97 A- \\
2.01 B-6.12 C-2.28 D-4.12 A B+ \\
2.64 A C-2.49 B C-2.00 A B C\end{array}$ & $\begin{array}{l}Ð=+0.12+9.283 E-003 A+1.294 E-003 B- \\
0.016 C-8.627 E-003 D+9.323 E-003 A B+ \\
7.70 I E-003 A C+0.012 B C\end{array}$ & $\begin{array}{l}\mathbf{Z P}=-21.41-1.03 A+2.17 B+ \\
0.84 C+0.80 D+6.250 E-003 A B- \\
1.18 A C+0.69 A D-0.60 B C+0.66 A B C\end{array}$ \\
\hline TENa & $\begin{array}{l}\text { Size }=+119.26-28.15 A-6.56 B- \\
1.64 C-2.77 D+5.21 A B+ \\
3.74 A C-1.24 B C\end{array}$ & $\begin{array}{l}\mathrm{D}=+0.1 \mathrm{I}-8.569 \mathrm{E}-004 \mathrm{~A}-3.665 \mathrm{E}-003 \mathrm{~B}+ \\
5.12 \mathrm{IE}-003 \mathrm{C}-6.806 \mathrm{E}-003 \mathrm{D}+1.065 \mathrm{E}- \\
003 \mathrm{AB}+8.361 \mathrm{E}-004 \mathrm{AD}+0.012 \mathrm{BC}+7.122 \mathrm{E}- \\
003 \mathrm{BD}+1.142 \mathrm{E}-003 \mathrm{CD}-9.853 \mathrm{E}-003 \mathrm{ABD}- \\
5.864 \mathrm{E}-003 \mathrm{BCD}\end{array}$ & $\begin{array}{l}\mathbf{Z P}=-28.15-2.02 A+0.78 B-2.77 C+ \\
I .40 D-0.054 A B-0.49 A C+0.57 A D+ \\
0.7 I B C-0.77 B D-0.56 C D- \\
0.78 A B C-0.53 A B D+0.40 A C D\end{array}$ \\
\hline TEL & $\begin{array}{l}\text { Size }=+139.40-22.20 A-7.50 B+ \\
3.96 C-4.60 D-2.53 A B+5.85 A C- \\
2.40 A D-7.49 B C+3.07 B D- \\
1.62 C D-6.93 A B C+3.40 A B D+ \\
0.16 A C D+1.36 B C D+2.10 A B C D\end{array}$ & $\begin{array}{l}\boldsymbol{D}=+0.18+0.02 I A+7.936 E-003 B- \\
5.342 E-003 C-0.012 D+2.633 E-003 A B- \\
9.533 E-003 A C-0.012 A D-0.02 I B C- \\
I .199 E-003 B D-5.365 E-003 C D+ \\
4.768 E-003 A B D\end{array}$ & $\begin{array}{l}\mathbf{Z P}=-19.85+1.29 A+0.80 B+1.32 C+ \\
2.20 D-1.36 A B+1.26 A C+1.27 A D- \\
0.66 B C+0.50 B D+0.69 C D+0.69 A B C- \\
0.47 A B D+0.05 I A C D+0.46 B C D- \\
1.13 A B C D\end{array}$ \\
\hline
\end{tabular}

Note: $A, B, C$, and $D$ refer to the independent variables selected for every factorial design experiment as illustrated in Table $I$.

Abbreviations: $\Theta$, dispersity; ZP, zeta potential; TET, transethosomes with Tween $20^{\circledR}$; TENa, transethosomes with sodium taurocholate; TEL, transethosomes with Labrafil ${ }^{\otimes}$. 


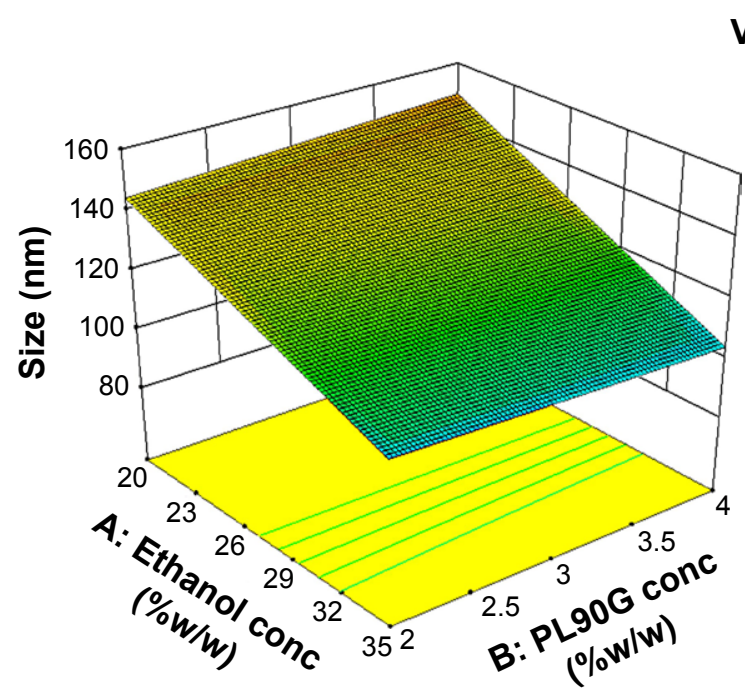

\section{Vesicular size}

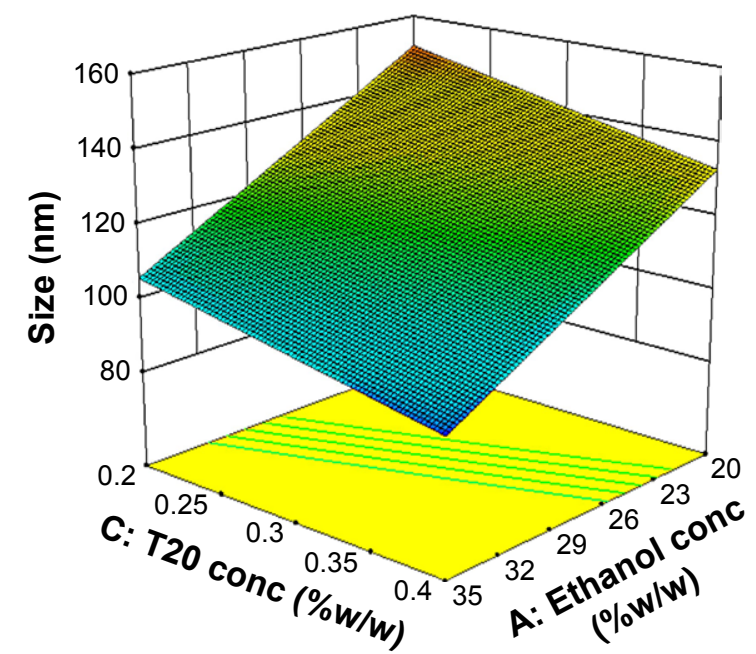

\section{Dispersity}
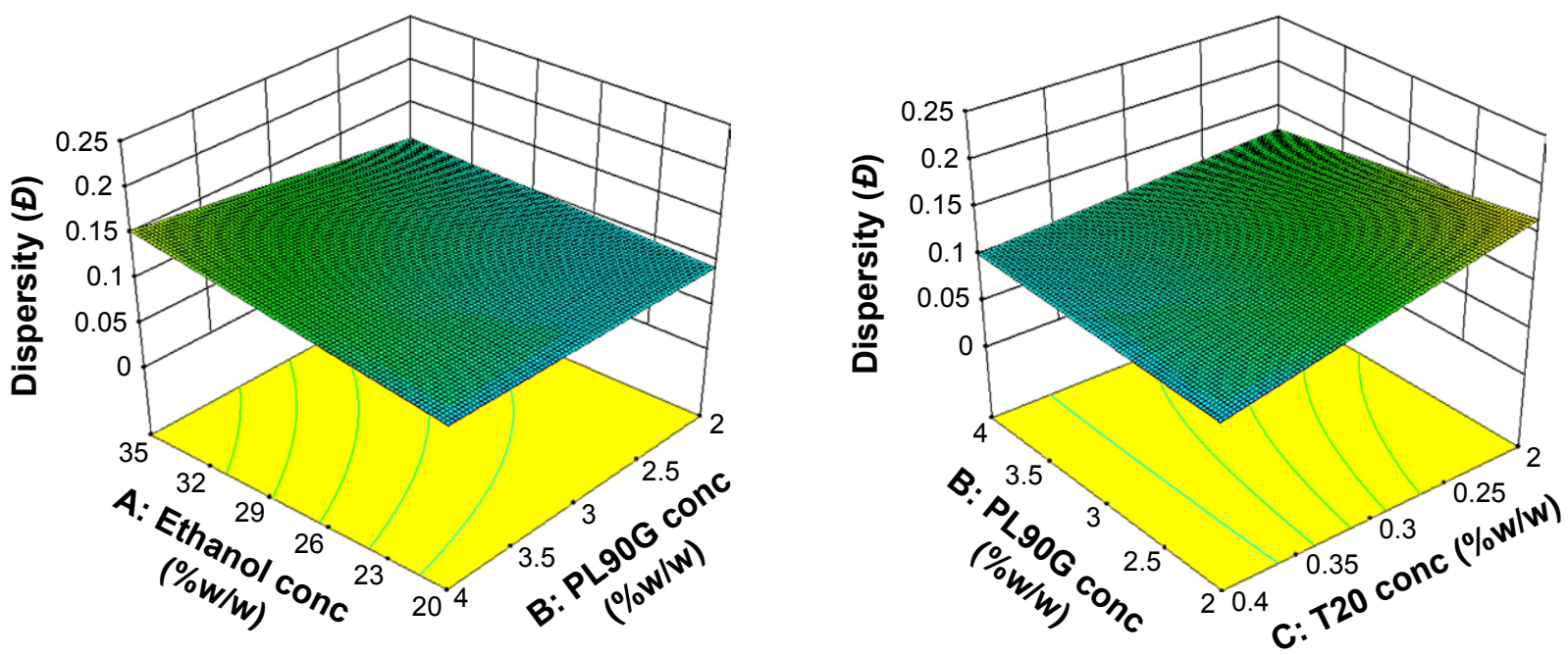

\section{Zeta potential}
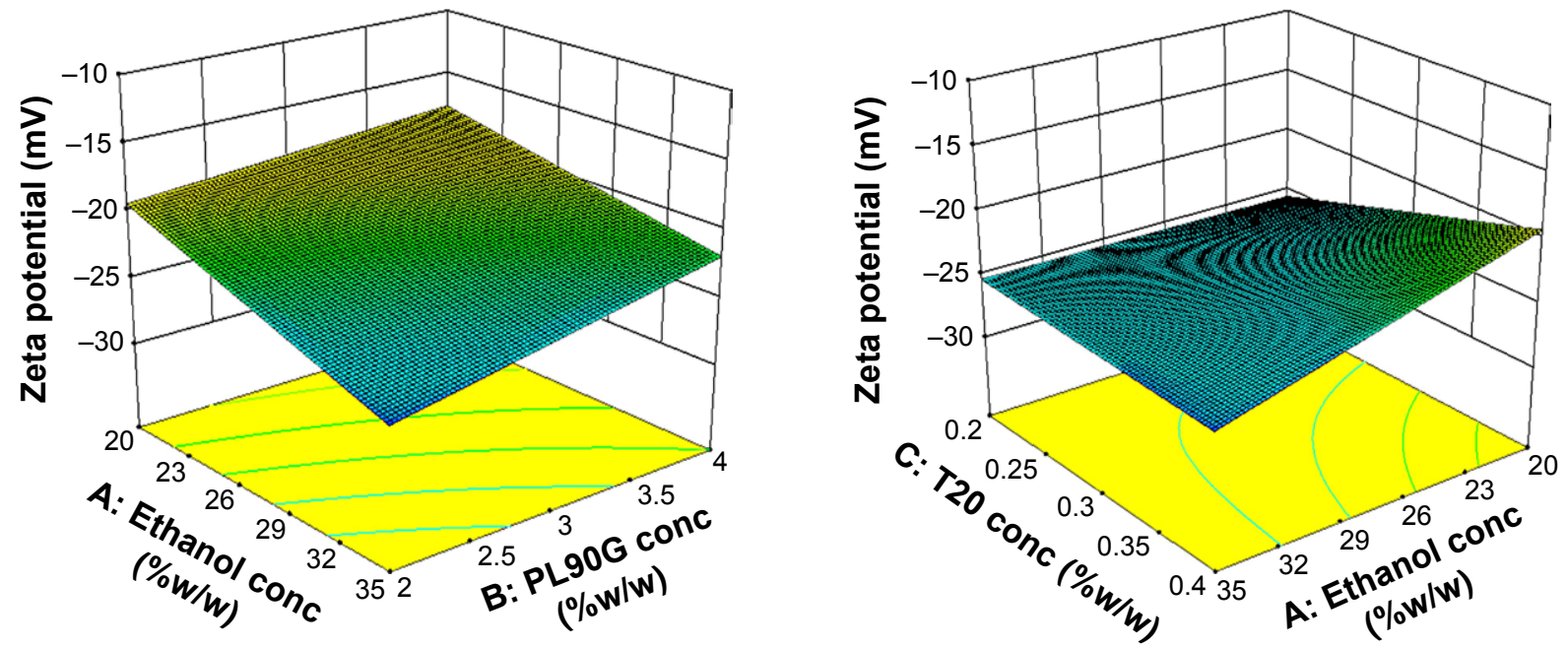

Figure I Response surface plots showing influences of the independent factors on the response parameters in TET design.

Abbreviations: PL90G, Phospholipon 90G ${ }^{\circledR}$; T20, Tween 20 ${ }^{\circledR}$; TET, transethosomes with Tween $20^{\circledR}$. 


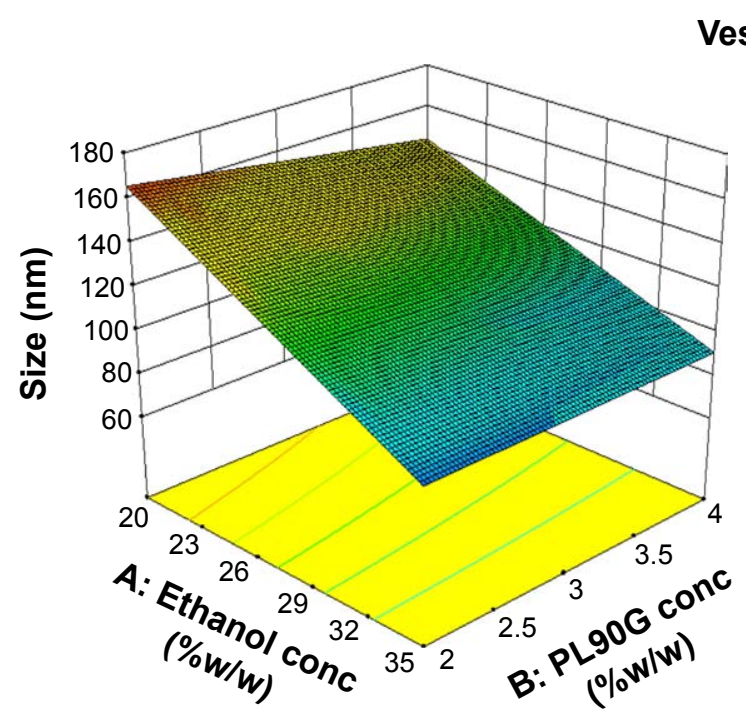

\section{Vesicular size}

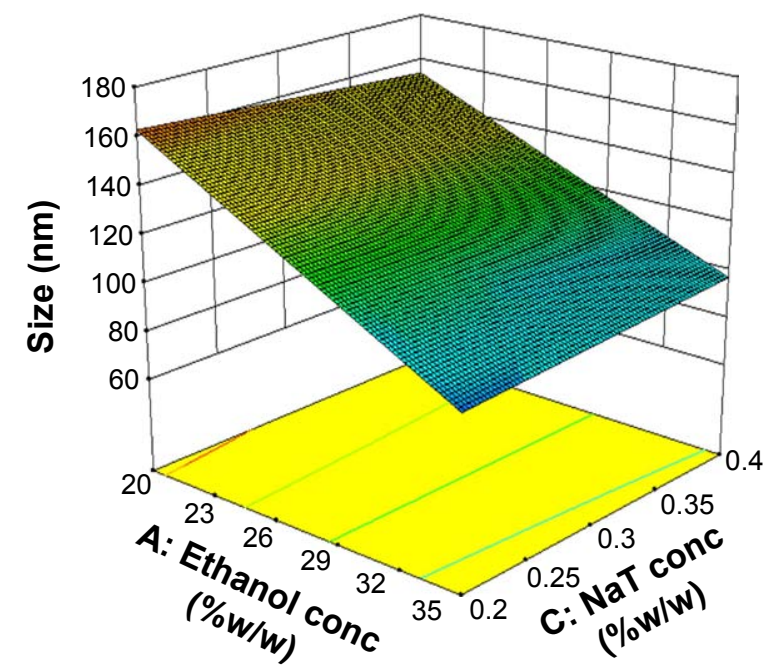

\section{Dispersity}
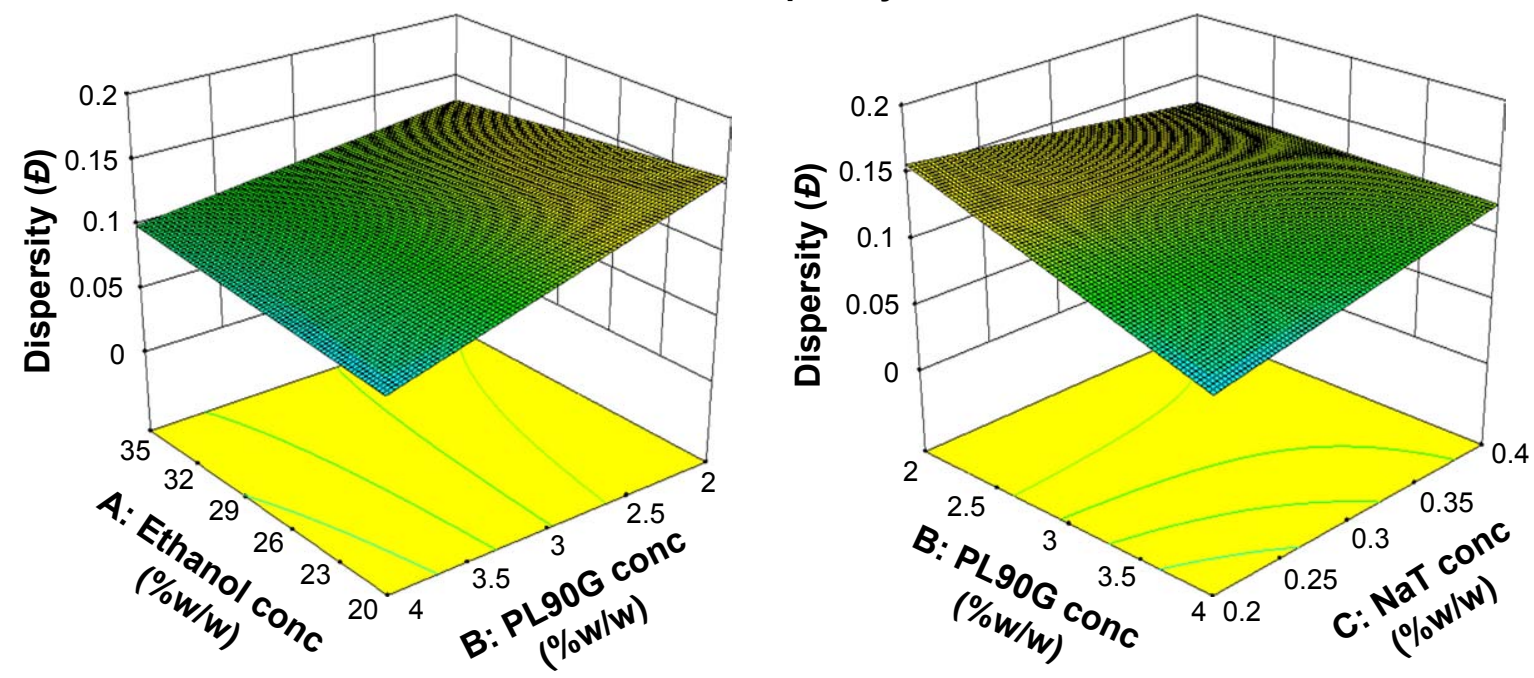

\section{Zeta potential}
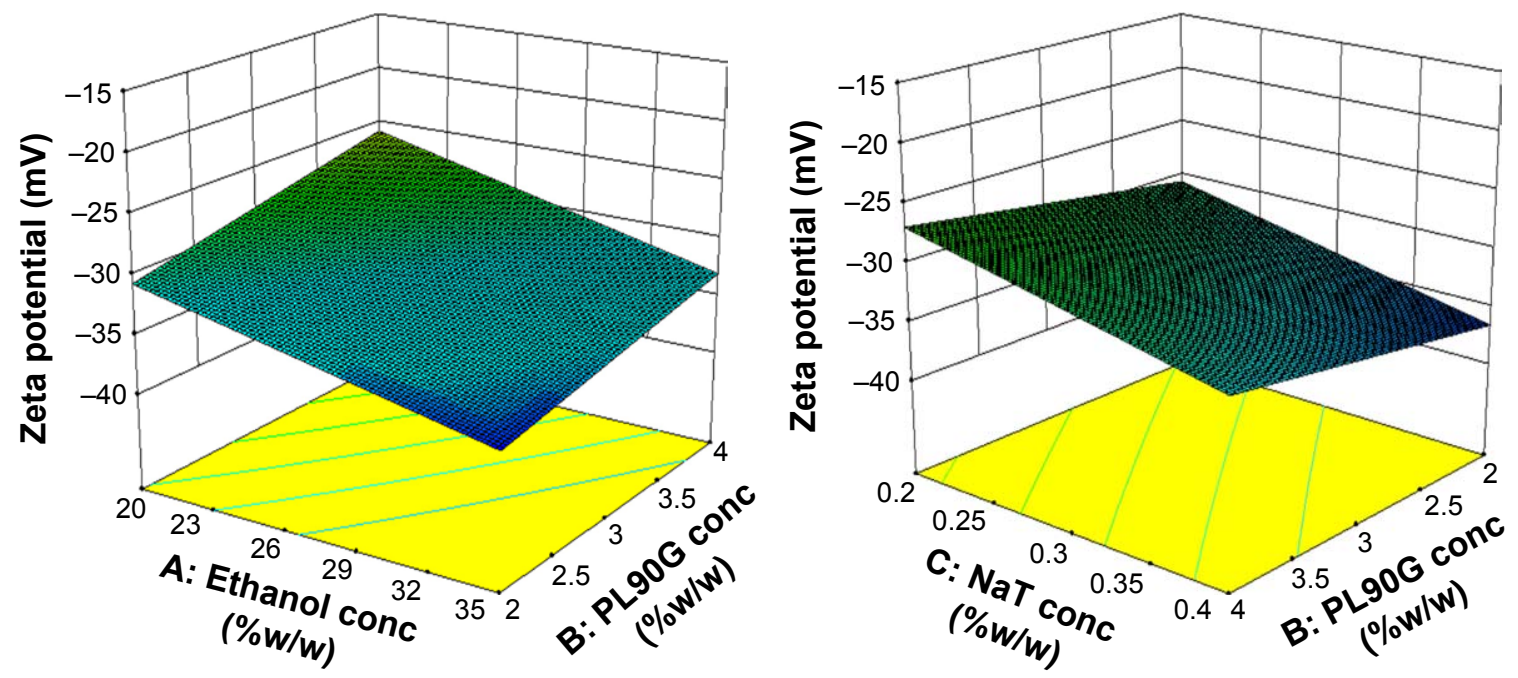

Figure 2 Response surface plots showing influences of the independent factors on the response parameters in TENa design. Abbreviations: PL90G, Phospholipon 90G ${ }^{\circledR}$; NaT, sodium taurocholate; TENa, transethosomes with sodium taurocholate. 


\section{Vesicular size}
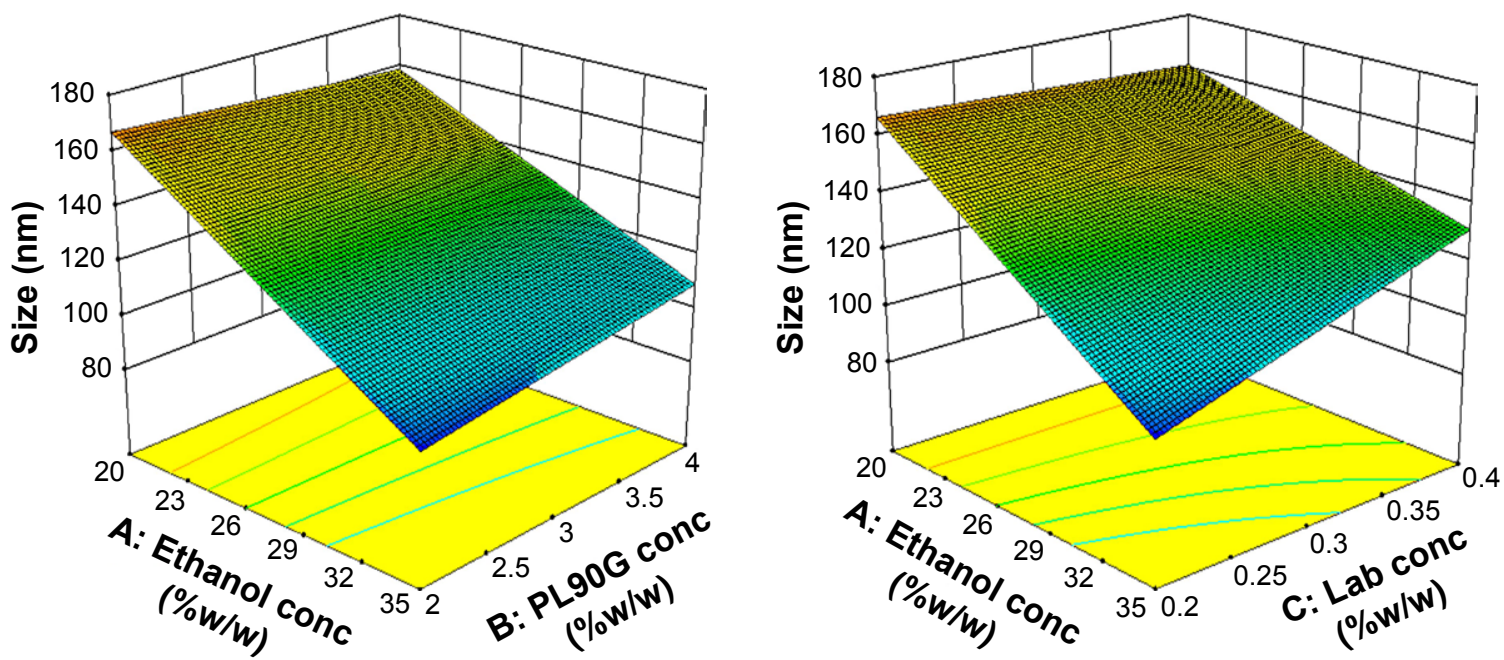

\section{Dispersity}
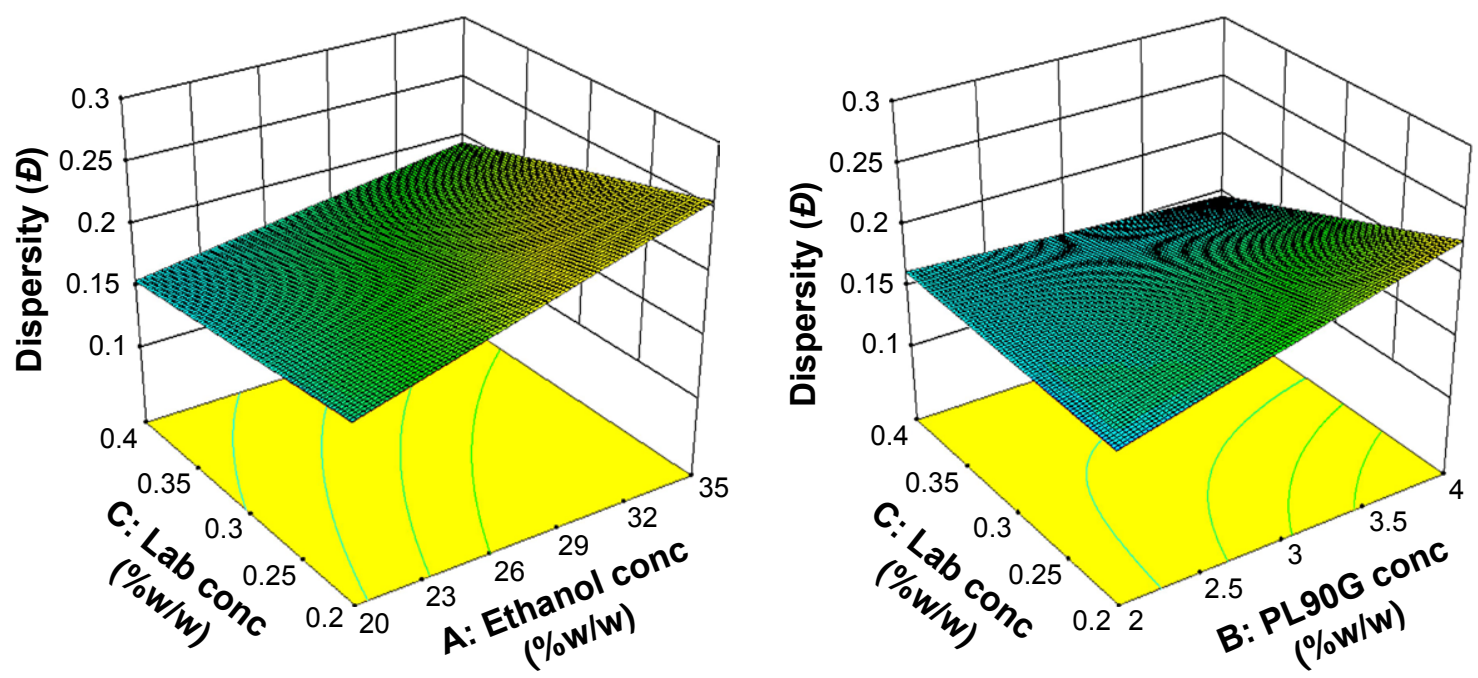

\section{Zeta potential}

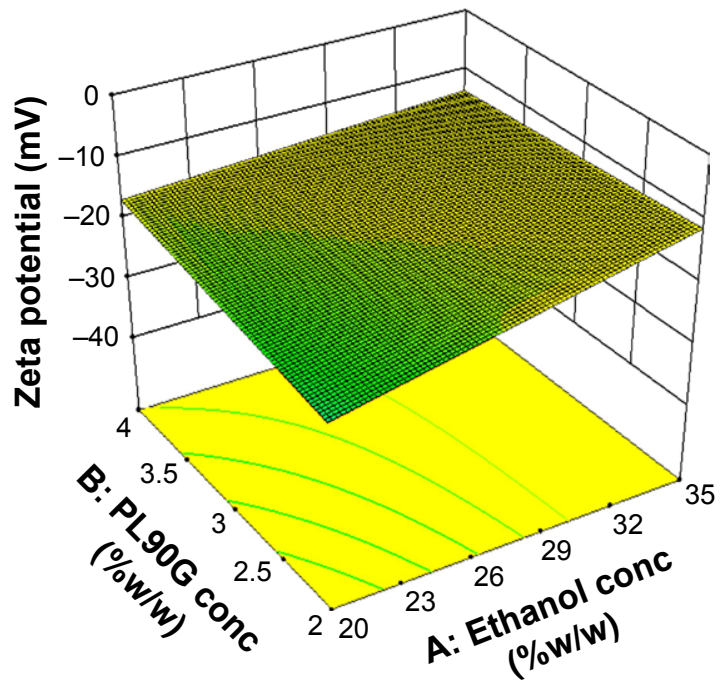

Figure 3 Response surface plots showing influences of the independent factors on the response parameters in TEL design.

Abbreviations: PL90G, Phospholipon 90G ${ }^{\circledR}$; Lab, Labrafil ${ }^{\circledR}$; TEL, transethosomes with Labrafi ${ }^{\circledR}$. 
Table 8 The effect (increase/decrease) of individual factors on the vesicular size, $\bigoplus$, and ZP in each design

\begin{tabular}{|c|c|c|c|c|c|c|}
\hline \multirow[t]{2}{*}{ Design } & \multicolumn{2}{|l|}{ Size } & \multicolumn{2}{|l|}{$\boldsymbol{\oplus}$} & \multicolumn{2}{|l|}{$\mathbf{Z P}$} \\
\hline & Increase & Decrease & Increase & Decrease & Increase & Decrease \\
\hline TET & - & $A^{*}, B, C^{*}, D^{*}$ & $A^{*}, B$ & C*, D & $A^{*}$ & $B^{*}, C^{*}, D^{*}$ \\
\hline TENa & - & $A^{*}, B^{*}, C^{*}, D^{*}$ & C & $A, B, D$ & $A^{*}, C^{*}$ & $B^{*}, D^{*}$ \\
\hline TEL & $C^{*}$ & $A^{*}, B^{*}, D^{*}$ & $A^{*}, B^{*}$ & C, D* & - & $A^{*}, B, C^{*}, D^{*}$ \\
\hline
\end{tabular}

Notes: A, B, C, and D refer to the independent variables selected for every factorial design experiment as illustrated in Table I. *Statistically significant $(p<0.05)$.

Abbreviations: $\oplus$, dispersity; ZP, zeta potential; TET, transethosomes with Tween $20^{\circledR}$; TENa, transethosomes with sodium taurocholate; TEL, transethosomes with Labrafil $^{\circledR}$.

the limit of $35 \% \mathrm{w} / \mathrm{w}$ caused an increase in the vesicular size and led to solubilization of the vesicles. This finding is in agreement with the previously published research regarding the ethanol effects on the vesicular size. The size reduction is probably due to the considerable reduction in vesicular membrane thickness as a result of interpenetration of ethanol hydrocarbon chain in the vesicular lipid bilayers. Ethanol may also cause a modification of the net charge of the system and gives some degree of steric stabilization that may finally lead to a decrease in the mean vesicular size ${ }^{39-42}$

Phospholipid concentration was reported to have some effects on the vesicular size, whereby increasing phospholipid concentration would increase the vesicular size. ${ }^{43}$ Similar effect of the phospholipids on the vesicular size of all the prepared TEs before extrusion was also observed. However, after extrusion, the size of all the vesicles was reduced to $<200 \mathrm{~nm}$.

The hydrophilic surfactants Tween $20^{\circledR}$ (hydrophiliclipophilic balance $[\mathrm{HLB}]=16.7$ ) and sodium taurocholate $($ HLB $=16)$ were found to significantly reduce $(p<0.05)$ the vesicular size of transethosomes with Tween $20^{\circledR}$ (TET) and TENa TEs, respectively as shown in Figures 1 and 2 . These results are in line with other findings reported by some researchers. ${ }^{17,44}$ In contrast, Labrafil ${ }^{\circledR}$ with lower HLB value ( $\mathrm{HLB}=9$ ) was found to have size-increasing effects, whereby increasing Labrafil ${ }^{\circledR}$ concentration increases the vesicular size significantly $(p<0.05)$ as illustrated in Figure 3. This effect might be attributed to the increased hydrophobicity of the surfactant and the interaction of the surfactant with the lipid bilayer. The latter two effects will in turn increase the packing density of the lipid bilayer leading to an increase in the surface free energy and consequently increase the fusion between the lipid bilayer and hence increase the vesicular size. ${ }^{45,46}$

The number of extrusions was found to have a significant impact $(p<0.05)$ on reducing the vesicular size of all the prepared TEs. Increasing the number of extrusions from 10 to 20 times significantly reduced the vesicular size. Similarly, increasing the number of extrusions also reduced the $Ð$ values of all the formulations.

\section{Effects of the formulation variables on the ZP}

Zeta potential is an important parameter that can affect vesicular properties, such as vesicle-skin interaction and TE stability. The results of the zeta potential analysis revealed that all the prepared TEs had negatively charged zeta potential, ranging from -10.58 to $-37 \mathrm{mV}$ as shown in Tables 3-5. Ogiso et al reported that the negatively charged vesicles had better skin permeation properties than the positively charged ones. ${ }^{47}$ The negative charge of the zeta potential of ethosomal systems is attributed mainly to the high ethanol content in these nanocarriers. Ethanol provides negative charges to the polar head groups of the phospholipids that would create an electrostatic repulsion. This would reduce the aggregation of ethosomal vesicles and hence enhance the stability of these nanocarriers.

The anionic surfactant sodium taurocholate had a significant $(p<0.05)$ positive impact on the zeta potential values of the prepared TENa formulations by providing negative surface charges to the vesicles. Increasing sodium taurocholate content was associated with a significant increase in the zeta potential values $(p<0.05)$ as illustrated in the ZP equation of the TENa formulations in Table 7 and in the 3D surface plot (Figure 2).

\section{Colchicine incorporation and optimization of EE\%}

Among all the designs, 23 formulations met the selection criteria of having vesicular size $\leq 150 \mathrm{~nm}, \oslash \leq 0.3$, and $\mathrm{ZP} \geq-20 \mathrm{mV}$. The selected TEs were loaded with $0.2 \% \mathrm{w} / \mathrm{w}$ of colchicine and then characterized for the vesicular size, $Ð$, ZP, and EE\% (Table 9).

Five formulations namely TET $2-0.2$, TET $6-0.2$, TET 14-0.2, TENa 4-0.2, and TENa 12-0.2 had EE\% $\geq 75 \%$, and they were chosen for further optimization. These TEs were loaded with colchicine at concentrations of 0.3 and $0.5 \% \mathrm{w} / \mathrm{w}$ and evaluated for the vesicular size, $Ð, \mathrm{ZP}$, and EE\% (Tables 10 and 11).

The vesicular size was still $<100 \mathrm{~nm}$ when colchicine concentration was increased to $0.3 \% \mathrm{w} / \mathrm{w}$. However, by 
Table 9 Characteristics of transethosomes loaded with $0.2 \% \mathrm{w} / \mathrm{w}$ of colchicine

\begin{tabular}{|c|c|c|c|c|c|}
\hline No & Code & Size $(\mathrm{nm})$ & $\boldsymbol{\oplus}$ & $\mathrm{ZP}(\mathrm{mV})$ & EE\% \\
\hline I & TET I-0.2 & $150.8 \pm 4.5$ & $0.108 \pm 0.003$ & $-22.16 \pm 1.35$ & $65.07 \pm 0.52$ \\
\hline 2 & TET $2-0.2$ & $92.7 \pm 2.9$ & $0.113 \pm 0.008$ & $-19.33 \pm 2.22$ & $78.54 \pm 3.4 I$ \\
\hline 3 & TET 4-0.2 & $95.6 \pm 1.4$ & $0.106 \pm 0.015$ & $-10.11 \pm 3.32$ & $65.58 \pm 3.35$ \\
\hline 4 & TET 6-0.2 & $87.5 \pm 1.6$ & $0.085 \pm 0.009$ & $-18.93 \pm I .37$ & $75.72 \pm 2.25$ \\
\hline 5 & TET 8-0.2 & $93.2 \pm 0.4$ & $0.108 \pm 0.009$ & $-14.33 \pm 2.33$ & $72.06 \pm 0.67$ \\
\hline 6 & TET 9-0.2 & $148.9 \pm 3.3$ & $0.130 \pm 0.003$ & $-|4.63 \pm 0.6|$ & $72.40 \pm 3.75$ \\
\hline 7 & TET I0-0.2 & $82.7 \pm 1.5$ & $0.118 \pm 0.003$ & $-18.6 \pm 0.49$ & $70.78 \pm 5.15$ \\
\hline 8 & TET | 4-0.2 & $79.8 \pm 1.9$ & $0.083 \pm 0.004$ & $-14.26 \pm 2.10$ & $83.57 \pm 0.84$ \\
\hline 9 & TENa 2-0.2 & $95.4 \pm 0.4$ & $0.163 \pm 0.032$ & $-30.43 \pm 0.41$ & $66.26 \pm 1.85$ \\
\hline 10 & TENa 3-0.2 & $145.7 \pm 4.9$ & $0.174 \pm 0.029$ & $-25.23 \pm 1.38$ & $64.30 \pm 1.18$ \\
\hline I I & TENa 4-0.2 & $96.2 \pm 0.8$ & $0.145 \pm 0.010$ & $-27.46 \pm 3.5 I$ & $75.2 I \pm 0.4 I$ \\
\hline 12 & TENa 6-0.2 & $99.2 \pm 0.8$ & $0.154 \pm 0.023$ & $-3|.3 \pm 3.3|$ & $66.52 \pm 1.57$ \\
\hline 13 & TENa 7-0.2 & $|4| .4 \pm \mid$ & $0.223 \pm 0.012$ & $-26.86 \pm 1.30$ & $68.22 \pm 0.52$ \\
\hline 14 & TENa 8-0.2 & $94.2 \pm 1.6$ & $0.139 \pm 0.014$ & $-31.66 \pm 2.49$ & $68.31 \pm 0.75$ \\
\hline 15 & TENa I0-0.2 & $89.9 \pm 2.5$ & $0.196 \pm 0.017$ & $-27.13 \pm 0.20$ & $74.53 \pm 3.47$ \\
\hline 16 & TENa I I-0.2 & $142.6 \pm 5.3$ & $0.165 \pm 0.027$ & $-22.6 \pm 0.96$ & $69.24 \pm 1.88$ \\
\hline 17 & TENa I 2-0.2 & $89.9 \pm 2.1$ & $0.134 \pm 0.012$ & $-20.43 \pm 0.47$ & $77.34 \pm 0.24$ \\
\hline 18 & TENa I4-0.2 & $94.8 \pm 2$ & $0.149 \pm 0.006$ & $-30.16 \pm 2.50$ & $71.55 \pm 0.63$ \\
\hline 19 & TENa I5-0.2 & $133.1 \pm 2.6$ & $0.153 \pm 0.002$ & $-23.56 \pm 2.18$ & $66.94 \pm 1.73$ \\
\hline 20 & TENa $16-0.2$ & $84.2 \pm 0.6$ & $0.133 \pm 0.010$ & $-27.46 \pm|.5|$ & $67.20 \pm 0.52$ \\
\hline 21 & TEL 2-0.2 & $108.5 \pm 1.4$ & $0.240 \pm 0.003$ & $-11.73 \pm 1.19$ & $72.74 \pm 6.08$ \\
\hline 22 & TEL 4-0.2 & $118.9 \pm 2.8$ & $0.183 \pm 0.006$ & $-25.13 \pm 2.74$ & $60.04 \pm 0.52$ \\
\hline 23 & TEL 8-0.2 & $|72| \pm 20$. & $0.692 \pm 0.042$ & $-26.63 \pm 1.91$ & $69.07 \pm 0.83$ \\
\hline
\end{tabular}

Notes: Each value is expressed as mean \pm standard deviation $(n=3)$. All formulations shown in bold had EE $\%$ values $>75 \%$ and were selected for further studies. Abbreviations: $€$, dispersity; ZP, zeta potential; EE\%, entrapment efficiency; TET, transethosomes with Tween $20^{\circledR}$; TENa, transethosomes with sodium taurocholate; TEL, transethosomes with Labrafil ${ }^{\circledast}$.

further increasing the drug concentration to $0.5 \% \mathrm{w} / \mathrm{w}$, the vesicular size of all the formulations increased to $>100 \mathrm{~nm}$. The $Ð$ values of all the selected formulations were $<0.3$ at all the studied concentrations. The ZP values of the TEs decreased significantly $(p<0.05)$ by increasing the drug concentration. The lowest $\mathrm{ZP}$ values were observed at a colchicine concentration of $0.5 \% \mathrm{w} / \mathrm{w}$. Colchicine is highly hydrophilic and a neutral drug, thus it may present in the aqueous phase of the inter-bilayer regions of the vesicles. This will reduce the negative charges generated by ethanol and hence will decrease the ZP values. It was found that increasing colchicine concentration from 0.2 to $0.3 \% \mathrm{w} / \mathrm{w}$ had no statistically significant effects on the $\mathrm{EE} \%$ of all the formulations, except TET 14-0.3, where the EE\% decreased significantly. However, increasing colchicine concentration further to $0.5 \% \mathrm{w} / \mathrm{w}$ caused a significant decrease $(p<0.05)$ in the $\mathrm{EE} \%(<75 \%)$ of all the studied formulations.

Colchicine concentration of $0.2 \% \mathrm{w} / \mathrm{w}$ is too low and is practically not suitable for the next step of the formulation process, which involves the development of transethosomal gels. The drug concentration of $0.5 \% \mathrm{w} / \mathrm{w}$ was also excluded from the selection due to the associated significant $(p<0.05)$ increase in the vesicular size and the significant decrease in the EE\% $(p<0.05)$. Therefore, colchicine concentration of $0.3 \% \mathrm{w} / \mathrm{w}$ was selected as the optimized drug concentration to be loaded into TEs as it produced high EE\% and small vesicular size. Accordingly, the TET 2-0.3, TET 14-0.3, TENa 4-0.3, and TENa

Table 10 Characteristics of transethosomes loaded with $0.3 \% \mathrm{w} / \mathrm{w}$ of colchicine

\begin{tabular}{|c|c|c|c|c|c|}
\hline No & Code & Size $(\mathrm{nm})$ & $\boxplus$ & $\mathrm{ZP}(\mathrm{mV})$ & EE\% \\
\hline I & TET 2-0.3 & $91.0 \pm 3.6$ & $0.1 I I \pm 0.015$ & $-19.86 \pm 0.77$ & $78.84 \pm 0.65$ \\
\hline 2 & TET 6-0.3 & $89.1 \pm 4.3$ & $0.131 \pm 0.022$ & $-23.00 \pm 1.66$ & $73.44 \pm 0.57$ \\
\hline 3 & TET | 4-0.3 & $87.6 \pm 3.0$ & $0.197 \pm 0.040$ & $-15.16 \pm 0.57$ & $76.74 \pm 0.77$ \\
\hline 4 & TENa 4-0.3 & $90.4 \pm 2.2$ & $0.090 \pm 0.004$ & $-24.76 \pm 2.29$ & $76.45 \pm 0.85$ \\
\hline 5 & TENa I 2-0.3 & $87.6 \pm 1.4$ & $0.109 \pm 0.009$ & $-20.86 \pm 1.09$ & $79.75 \pm 1.04$ \\
\hline
\end{tabular}

Notes: Each value is expressed as mean \pm standard deviation $(n=3)$. All formulations shown in bold had EE $\%$ values $>75 \%$ and were selected for further studies. Abbreviations: $\oplus$, dispersity; ZP, zeta potential; EE\%, entrapment efficiency; TET, transethosomes with Tween $20^{\circledR}$; TENa, transethosomes with sodium taurocholate. 
Table I I Characteristics of transethosomes loaded with $0.5 \% \mathrm{w} / \mathrm{w}$ of colchicine

\begin{tabular}{|c|c|c|c|c|c|}
\hline No & Code & Size $(n m)$ & $\boldsymbol{D}$ & $Z P(m V)$ & EE\% \\
\hline I & TET 2-0.5 & $104.0 \pm 0.2$ & $0.138 \pm 0.002$ & $-17.00 \pm 1.34$ & $69.37 \pm 1.46$ \\
\hline 2 & TET 6-0.5 & || $4.1 \pm 3.3$ & $0.148 \pm 0.02$ & $-18.00 \pm 2.08$ & $65.21 \pm 0.68$ \\
\hline 3 & TET I4-0.5 & $110.2 \pm 2.8$ & $0.125 \pm 0.011$ & $-17.73 \pm 1.73$ & $65.34 \pm 0.56$ \\
\hline 4 & TENa 4-0.5 & $|42| \pm 0.6$. & $0.132 \pm 0.003$ & $-13.83 \pm 1.38$ & $61.83 \pm 0.77$ \\
\hline 5 & TENa I2-0.5 & $138.2 \pm 1.3$ & $0.106 \pm 0.005$ & $-10.35 \pm 1.90$ & $63.98 \pm 1.12$ \\
\hline
\end{tabular}

Note: Each value is expressed as mean \pm standard deviation $(n=3)$.

Abbreviations: $\oslash$, dispersity; ZP, zeta potential; EE\%, entrapment efficiency; TET, transethosomes with Tween $20^{\circledast}$; TENa, transethosomes with sodium taurocholate.

12-0.3 formulations (with vesicular size $<100 \mathrm{~nm}$ and $\mathrm{EE} \%>75 \%$ ) were chosen for further studies for developing the transethosomal gels.

\section{Preparation of the transethosomal gels}

Carbopol ${ }^{\circledR}$ polymers (crosslinked polyacrylic acid polymers) are the commonly used gel-forming agents for the incorporation of ethosomal systems. In this study, Carbopol $940^{\circledR}$ was selected because it is compatible with ethosomal nanocarriers and has good bioadhesive properties. ${ }^{48}$ In the preliminary studies of the preparation of colchicine-loaded transethosomal gels, various concentrations $(0.5,1,1.5$, and $2 \% \mathrm{w} / \mathrm{w})$ of Carbopol $940^{\circledR}$ were tried, but only the concentration of $2 \% \mathrm{w} / \mathrm{w}$ gave suitable consistency (by visual observation) when mixed with the colchicine-loaded transethosomal suspensions.

Methyl paraben and propyl paraben were added to the gel base as preservatives. The four optimized transethosomal formulations (TET 2-0.3, TET 14-0.3, TENa 4-0.3, and TENa 12-0.3) were incorporated into the gel base. The physical appearance of all the prepared colchicine-loaded transethosomal gels was found to be translucent while the prepared NE gel was found to be transparent. The final concentration of colchicine in all the gel formulations was $0.24 \% \mathrm{w} / \mathrm{w}$; colchicine concentration $\leq 0.5 \%$ is considered safe for topical application. ${ }^{12,49}$ In addition, $0.5 \mathrm{~g}$ of the colchicineloaded transethosomal gel $(0.24 \% \mathrm{w} / \mathrm{w})$ is equivalent to the daily oral dose $(1.2 \mathrm{mg})$ of colchicine.

\section{Characterization of the colchicine-loaded transethosomal gels}

The characterization results of the colchicine-loaded transethosomal gels are summarized in Table 12. It was revealed that there was no significant difference between the various gels regarding the vesicular size, $\oslash, \mathrm{ZP}$, and $\mathrm{pH}$ values. However, the $\mathrm{ZP}$ magnitude of the transethosomal vesicles was notably increased after their incorporation into the Carbopol $940^{\circledR}$ gel base. This effect might be attributed to the anionic nature of the polyacrylic acid. The $\mathrm{pH}$ values of the prepared gels were in the range of 6.72-6.81, which are within the normal $\mathrm{pH}$ range of skin, thereby will not cause skin irritation upon application. ${ }^{30,50}$

The rheological behavior of the prepared gels was studied because it plays an important role in the flow characteristics of the materials during the mixing process, packaging into containers, storage, and application to the skin. The viscosity and yield values of TET transethosomal gels (TET 2-0.3 and TET 14-0.3) were significantly higher than those of TENa transethosomal gels (TENa 4-0.3 and TENa 12-0.3) $(p<0.05$ ). This might be attributed to the higher PL90G concentration $(4 \% \mathrm{w} / \mathrm{w})$ in TENa transethosomal gels, in comparison with its concentration $(2 \% \mathrm{w} / \mathrm{w})$ in the TET transethosomal gels. The yield values of all the colchicine-loaded transethosomal gels were in the range of 119.85-131.91 $\mathrm{Pa}$, which are within the desirable yield range $(<500 \mathrm{~Pa})$ for the topical drug delivery preparation. ${ }^{30}$ The rheograms of the various colchicineloaded transethosomal gels revealed that all the prepared gels exhibited non-Newtonian plastic flow and fitted the Bingham model of rheological behavior. In addition, all the prepared gels exhibited no thixotropy because no hysteresis loops were seen in the rheograms, ${ }^{51}$ reflecting no time-dependent decrease in viscosity under stress and stable structure of the polymer used in the preparation, as illustrated in Figure 4.

Among the studied colchicine-loaded transethosomal gel formulations (TET 2-0.3, TET 14-0.3, TENa 4-0.3, and TENa 12-0.3), two formulations (TET 2-0.3 and TENa 4-0.3), which had the highest yield values, were selected for the

Table 12 Characterization of various colchicine-loaded transethosomal gels

\begin{tabular}{|c|c|c|c|c|}
\hline Parameter & TET 2-0.3 & TET I4-0.3 & TENa 4-0.3 & TENa I 2-0.3 \\
\hline Size $(\mathrm{nm})$ & $111.4 \pm 1.6$ & $112.7 \pm 1.1$ & $I 10.5 \pm I . I$ & $108.4 \pm 1.5$ \\
\hline$\bigoplus$ & $0.157 \pm 0.01$ & $0.159 \pm 0.012$ & $0.162 \pm 0.014$ & $0.153 \pm 0.01$ \\
\hline $\mathrm{ZP}(\mathrm{mV})$ & $-40.56 \pm 5.32$ & $-41.25 \pm 3.24$ & $-43.54 \pm 2.56$ & $-43 \pm 1.64$ \\
\hline $\mathrm{pH}$ & $6.74 \pm 0.05$ & $6.75 \pm 0.05$ & $6.8 \mathrm{I} \pm 0.04$ & $6.72 \pm 0.03$ \\
\hline Viscosity (Pa.s) & $66.25 \pm 2.75$ & $60.22 \pm 0.5 I$ & $55.68 \pm 0.76$ & $53.56 \pm 1.43$ \\
\hline Yield (Pa) & $131.91 \pm 1.94$ & $128.55 \pm 0.98$ & $|22.7| \pm 0.99$ & $119.85 \pm 1.98$ \\
\hline
\end{tabular}

Notes: Each value is expressed as mean \pm standard deviation $(n=3)$. All formulations shown in bold were selected for further studies. Abbreviations: $\oplus$, dispersity; ZP, zeta potential; TET, transethosomes with Tween $20^{\circledR}$; TENa, transethosomes with sodium taurocholate. 
A

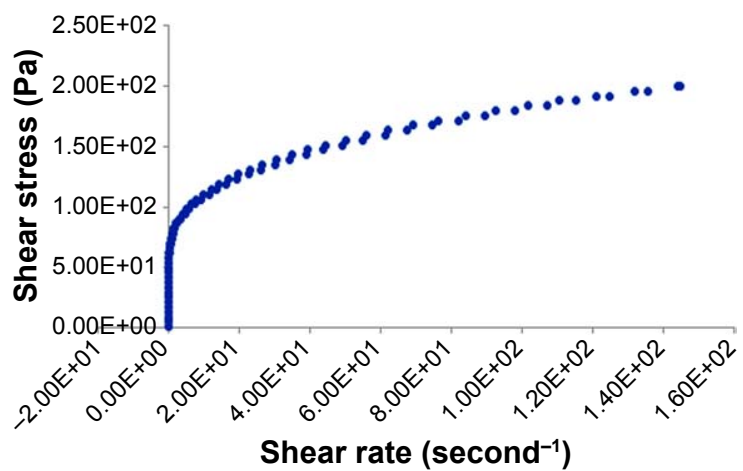

C

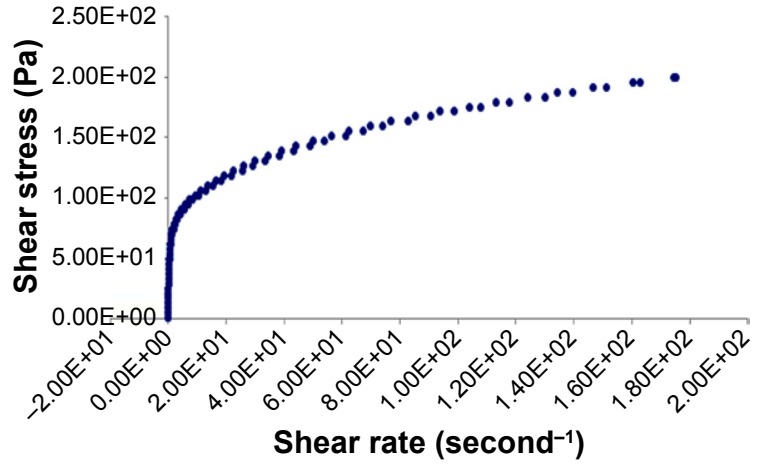

B

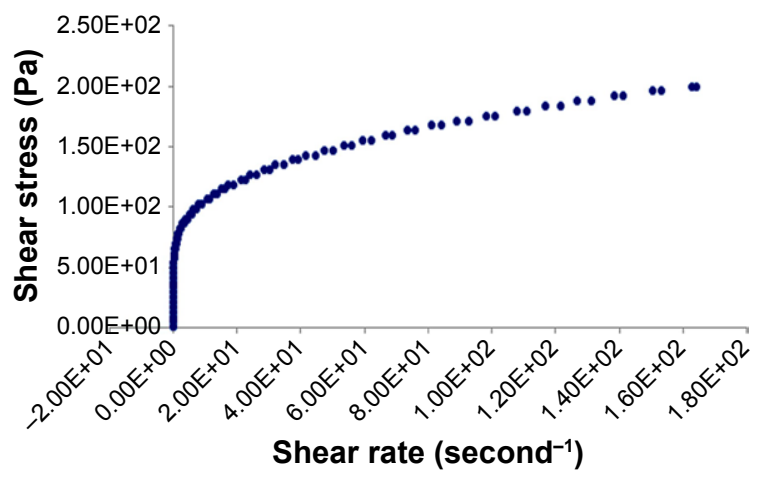

D

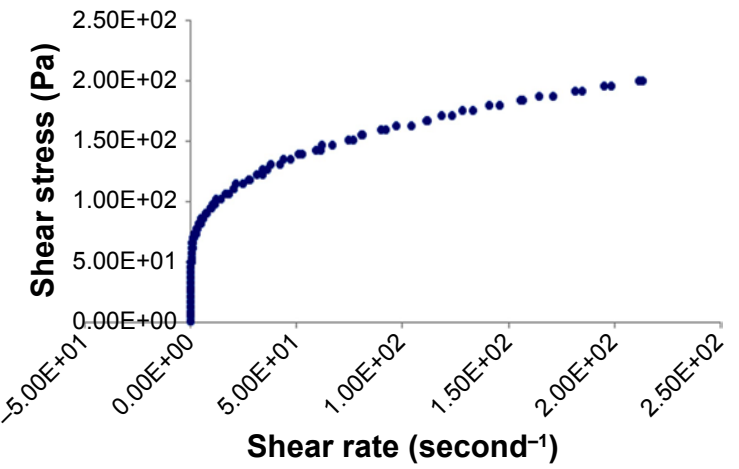

Figure 4 Representative rheograms of the prepared transethosomal gels.

Notes: (A) TET 2-0.3 gel; (B) TET I4-0.3 gel; (C) TENa 4-0.3 gel; (D) TENa I2-0.3 gel.

ex vivo skin permeation study. This is because formulations with higher static yield values are expected to be more stable by maintaining the vesicles in suspension and minimizing sedimentation.

\section{Ex vivo skin permeation studies}

The ex vivo skin permeation experiments were conducted using full-thickness-excised rats' back skin to determine and compare the skin permeation parameters between colchicine-loaded transethosomal gels (TET 2-0.3 and TENa 4-0.3) and the NE colchicine gel formula. All the gels contained the same concentration of the drug $(0.24 \% \mathrm{w} / \mathrm{w})$. The cumulative amounts of colchicine permeated per unit area from the different gel formulations are shown in Figure 5. It was noted that the amounts of colchicine permeated (after 24 hours) through rats' skin from the transethosomal

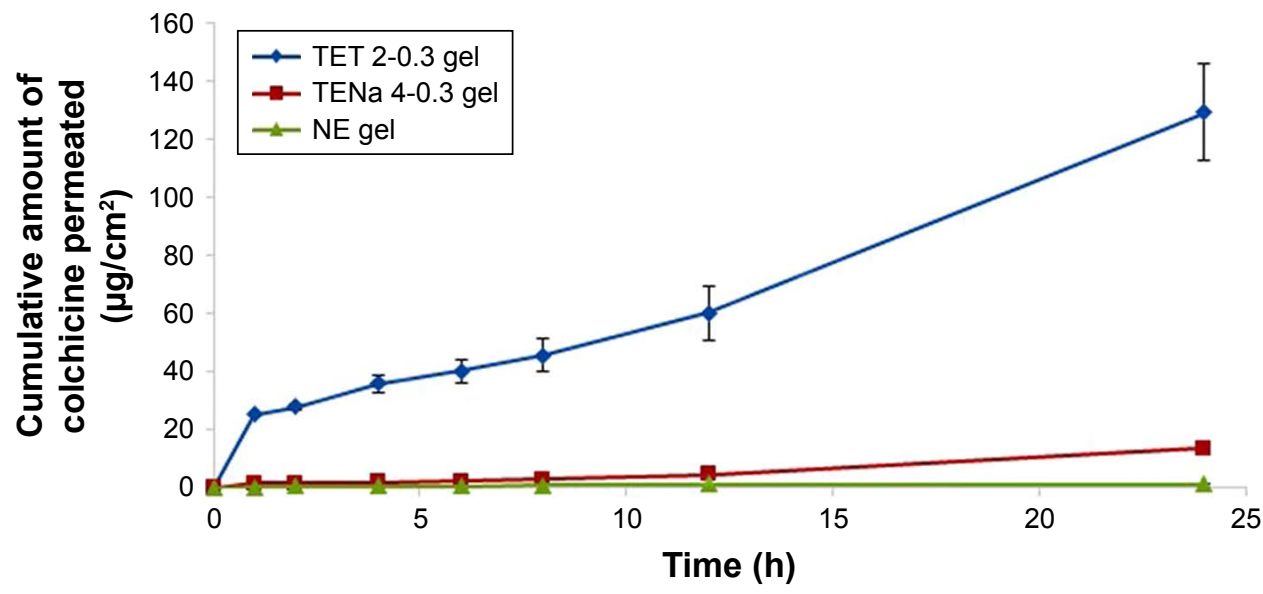

Figure 5 Ex vivo skin permeation of colchicine from various gels.

Note: The data are represented as mean \pm standard deviation $(n=3)$.

Abbreviations: NE, non-ethosomal; TET, transethosomes with Tween $20^{\circledR}$; TENa, transethosomes with sodium taurocholate. 
Table 13 The flux at steady state $\left(U_{s s}\right)$ and the permeability coefficient $\left(K_{p}\right)$ of colchicine from various gels through rat skin

\begin{tabular}{lll}
\hline Code & $\mathbf{J}_{\text {ss }}\left(\mu \mathrm{g} / \mathrm{cm}^{2} / \mathbf{h}\right)$ & $\mathbf{K p ~}(\mathbf{c m} / \mathbf{h})$ \\
\hline TET 2-0.3 gel & $7.233 \pm \mathrm{I} . \mathrm{I}$ & $0.003 \mathrm{I} \pm 0.0005$ \\
TENa 4-0.3 gel & $\mathrm{I} .084 \pm 0.04$ & $0.0005 \pm \mathrm{IE}-05$ \\
NE gel & $0.063 \pm 0.01$ & $0.00003 \pm 2 \mathrm{E}-06$ \\
\hline
\end{tabular}

Note: Each value is expressed as mean \pm standard deviation $(n=3)$.

Abbreviations: NE, non-ethosomal; TET, transethosomes with Tween 20 ${ }^{\circledR}$; $\mathrm{TENa}$, transethosomes with sodium taurocholate.

gels TET 2-0.3 $\left(129.14 \pm 16.53 \mu \mathrm{g} / \mathrm{cm}^{2}\right)$ and TENa 4-0.3 $\left(13.65 \pm 0.45 \mu \mathrm{g} / \mathrm{cm}^{2}\right)$ were significantly $(p<0.05)$ higher than the NE gel $\left(1.41 \pm 0.07 \mu \mathrm{g} / \mathrm{cm}^{2}\right)$.

The flux $\left(\mathrm{J}_{\mathrm{ss}}\right)$ and permeation coefficient $(\mathrm{Kp})$ values of the tested formulations are summarized in Table 13. There were significant differences $(p<0.05)$ in the flux and $\mathrm{Kp}$ values among the studied gels. The highest flux was obtained from TET 2-0.3 gel $\left(7.233 \pm 1.1 \mu \mathrm{g} / \mathrm{cm}^{2} / \mathrm{h}\right)$ followed by TENa 4-0.3 (1.084 \pm 0.04$)$, while the flux of the NE gel was $0.063 \pm 0.01 \mu \mathrm{g} / \mathrm{cm}^{2} / \mathrm{h}$.

The significantly enhanced skin permeation of colchicine from the transethosomal gels (TET 2-0.3 and TENa 4-0.3) over the NE gel is attributed to the presence of ethanol, phospholipids, and surfactants. These substances are acting synergistically to enhance the skin permeation of colchicine by increasing the malleability of vesicles and the perturbation of the skin lipids, at the same time, leading to a higher number of TEs that reach the deeper layers of the skin and release the drug. ${ }^{19,21,44,52}$

The type of edge activator used in the preparation of the TEs also played a significant role in enhancing the skin permeation of colchicine from the prepared gels. The TET 2-0.3

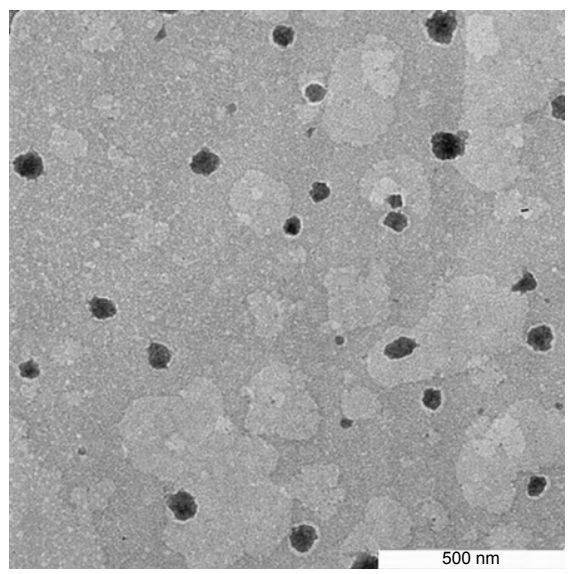

TET 2-0.3 transethosomal suspension gel that contains Tween $20^{\circledR}$ (nonionic surfactant, HLB $=16.7$ ) had significantly better skin permeation properties than TENa 4-0.3 gel that contains sodium taurocholate (anionic surfactant, HLB =16). This could be due to the higher vesicular deformability provided by Tween $20^{\circledR}$ than for sodium taurocholate, leading to higher skin permeation. Tween $20^{\circledR}$ was reported to provide significantly higher vesicular deformability in comparison to sodium taurocholate and other bile salts in retinol-loaded deformable liposomes. ${ }^{53}$ Based on the obtained results, TET 2-0.3 gel was selected as the optimized colchicine-loaded transethosomal gel formulation and was subjected to further studies of TEM and stability.

\section{TEM}

The morphology of the optimized TET 2-0.3 formulation was visualized by the TEM in the initial suspension form and after incorporation into the gel base, as shown in Figure 6. The TEs of TET 2-0.3 formulation in both the forms had irregular spherical shape. This might be attributed to the presence of surfactant (Tween $20^{\circledR}$ ) in the composition of the vesicles which perturbed the lipid bilayer and increased their fluidity. ${ }^{17}$

\section{Stability studies}

The results of the stability studies of TET 2-0.3 gel in both the conditions, $4^{\circ} \mathrm{C} \pm 2{ }^{\circ} \mathrm{C}$ and $25^{\circ} \mathrm{C} \pm 2{ }^{\circ} \mathrm{C} / 60 \% \pm 5 \% \mathrm{RH}$, are summarized in Tables 14 and 15 . The physical stability of TET 2-0.3 formulation was observed visually. It was found that the appearance of the TET 2-0.3 gel formulation was unchanged during the 3 months of storage at the refrigerated $\left(4^{\circ} \mathrm{C} \pm 2^{\circ} \mathrm{C}\right)$ or room temperature $\left(25^{\circ} \mathrm{C} \pm 2{ }^{\circ} \mathrm{C} / 60 \% \pm 5 \% \mathrm{RH}\right)$ conditions.

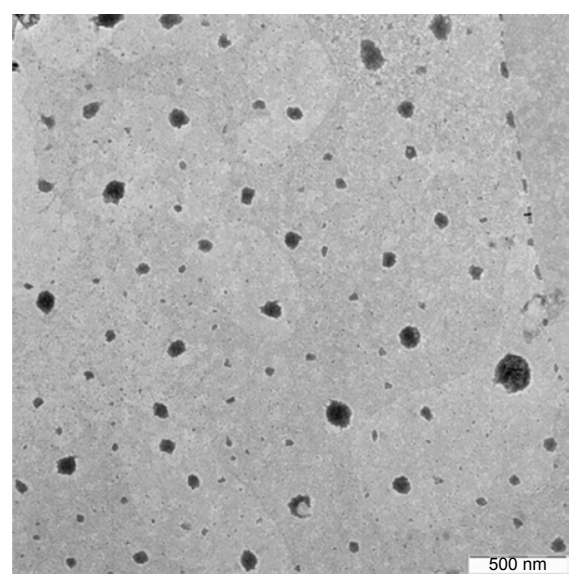

TET 2-0.3 transethosomal gel

Figure 6 TEM images of TET 2-0.3 transethosomes in its suspension and transethosomal gel forms. Abbreviations: TEM, transmission electron microscopy; TET, transethosomes with Tween $20^{\circledR}$. 
Table I4 Stability study results of the TET 2-0.3 gel stored at $4^{\circ} \mathrm{C} \pm 2^{\circ} \mathrm{C}$

\begin{tabular}{|c|c|c|c|c|}
\hline \multirow[t]{2}{*}{ Parameters } & \multirow[t]{2}{*}{0 months } & \multicolumn{3}{|l|}{$4^{\circ} \mathrm{C} \pm 2^{\circ} \mathrm{C}$} \\
\hline & & Ist month & 2nd month & 3rd month \\
\hline U. & $111.4 \pm 1.6$ & $119.4 \pm 1.9$ & $130.5 \pm 1.8$ & $|4| .7 \pm 1.8$ \\
\hline$\oslash$ & $0.157 \pm 0.01$ & $0.145 \pm 0.013$ & $0.152 \pm 0.015$ & $0.156 \pm 0.012$ \\
\hline $\mathrm{ZP}(\mathrm{mV})$ & $-40.56 \pm 5.32$ & $-39.2 \pm 2.23$ & $-38.3 \pm 4.64$ & $-47.3 \pm 1.2$ \\
\hline $\mathrm{pH}$ & $6.74 \pm 0.05$ & $6.77 \pm 0.14$ & $6.8 \pm 0.04$ & $6.88 \pm 0.09$ \\
\hline Drug content & $99.94 \pm 0.32$ & $99.98 \pm 0.36$ & $99.06 \pm 1.16$ & $99.16 \pm 0.47$ \\
\hline Viscosity $(\mathrm{Pa} \cdot \mathrm{s})$ & $66.25 \pm 2.75$ & $66.84 \pm 2.36$ & $66.69 \pm 2.48$ & $66.81 \pm 1.9$ \\
\hline Yield $(\mathrm{Pa})$ & $\mid 31.91 \pm 1.94$ & $\mid 32.17 \pm 1.38$ & $131.6 \pm 1.26$ & $132.03 \pm 1.25$ \\
\hline
\end{tabular}

Note: Each value is expressed as mean \pm standard deviation $(n=3)$.

Abbreviations: $\Theta$, dispersity; ZP, zeta potential; TET, transethosomes with Tween $20^{\circledR}$.

The vesicular size of TET 2-0.3 gel was found to increase slightly, by $\sim 30 \mathrm{~nm}$ only, in the overall 3 month storage period at the refrigerated storage condition $\left(4^{\circ} \mathrm{C} \pm 2^{\circ} \mathrm{C}\right)$. However, this increment was found to be statistically significant $(p<0.05)$. On the other hand, the vesicular size of TET 2-0.3 gel samples stored at $25^{\circ} \mathrm{C} \pm 2{ }^{\circ} \mathrm{C} / 60 \% \pm 5 \% \mathrm{RH}$ was increased by $\sim 30 \mathrm{~nm}$ in the first month and $\sim 50 \mathrm{~nm}$ in the overall 3 months of storage. There were no significant changes $(p>0.05)$ in $\oslash$ and $\mathrm{ZP}$ values during the 3 month study period under both the tested storage conditions.

The $\mathrm{pH}$ values of the TET 2-0.3 gel samples remained stable at the refrigerated storage condition for the 3 month period. Similarly, no changes in the $\mathrm{pH}$ were observed in the first 2 months at the room temperature condition, but a slight increase in $\mathrm{pH}$ occured in the third month. However, all the $\mathrm{pH}$ values under both the storage conditions and over the 3 month period were within the normal $\mathrm{pH}$ range of the skin.

No significant $(p>0.05)$ variation in drug content was observed over the 3 months of the stability study in the refrigerated storage condition. In contrast, the drug content in the samples stored at room temperature was stable in the

Table I 5 Stability study results of the TET 2-0.3 gel stored at $25^{\circ} \mathrm{C} \pm 2^{\circ} \mathrm{C} / 60 \% \pm 5 \% \mathrm{RH}$

\begin{tabular}{|c|c|c|c|c|}
\hline \multirow[t]{2}{*}{ Parameters } & \multirow[t]{2}{*}{0 months } & \multicolumn{3}{|c|}{$25^{\circ} \mathrm{C} \pm 2^{\circ} \mathrm{C} / 60 \% \pm 5 \% \mathbf{R H}$} \\
\hline & & Ist $n$ & 2nd month & $3 r d$ \\
\hline & 0 & 140.7 & 150.1 & $162.1 \pm 2.1$ \\
\hline 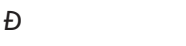 & .01 & 0.173 & 0.155 & $0.176 \pm 0.021$ \\
\hline ZP ( & -4 & -36 & & -44 \\
\hline $\mathrm{pH}$ & $6.74 \pm 0.05$ & $6.76 \pm$ & $6.85 \pm$ & $7.07 \pm 0.14$ \\
\hline Drug c & $99.94 \pm 0.32$ & 99.34 & $97.62 \pm 0.74$ & $95.96 \pm 0.61$ \\
\hline Viscosity (Pa.s) & $66.25 \pm 2.75$ & $66.86 \pm 2.12$ & $66.51 \pm 1.92$ & $66.01 \pm 2.6$ \\
\hline Yield $(\mathrm{Pa})$ & $131.91 \pm 1.94$ & $|31.94 \pm 1.1|$ & $|3| .54 \pm|.3|$ & $|32.0| \pm 2.22$ \\
\hline
\end{tabular}

Note: Each value is expressed as mean \pm standard deviation $(n=3)$.

Abbreviations: $\bigoplus$, dispersity; ZP, zeta potential; $\mathrm{RH}$, relative humidity; TET, transethosomes with Tween $20^{\circledR}$. first month only, thereafter it started to decrease significantly $(p<0.05)$. The decrease in drug content might be due to the chemical degradation of the phospholipids in the transethosomal vesicles, which disturbed the membrane packing, and eventually led to drug leakage. ${ }^{54}$ No significant changes were observed in the viscosity, yield values, and the rheological behavior of the TET 2-0.3 gel samples under both the tested storage conditions and over the 3 month period of the stability study.

\section{Conclusion}

Colchicine-loaded transethosomal gels were successfully developed and optimized using three $2^{4}$ full factorial experimental designs. The optimized formulation had suitable characteristics for the transdermal delivery of drugs, such as small vesicular size, negatively charged ZP, and high EE\%. The ex vivo skin permeation studies revealed that the transethosomal gels had superior skin permeation properties in comparison to the NE gel formulation. The stability studies showed that the optimized colchicine-loaded transethosomal gel had satisfactory stability at the refrigerated condition $\left(4^{\circ} \mathrm{C} \pm 2^{\circ} \mathrm{C}\right)$. Therefore, it is concluded that transethosomal gels are potential carriers for the transdermal delivery of colchicine. These carriers provide an alternative route for the administration of this drug to overcome the poor bioavailability and severe side effects associated with the oral route.

\section{Acknowledgments}

The authors would like to thank Universiti Sains Malaysia for providing research University grant (1001/PFarmasi/811285) to support this work. The author Ibrahim M Abdulbaqi gratefully acknowledges Universiti Sains Malaysia, Penang, Malaysia, for the granting of a Graduate Assistantship. The authors would also like to thank Ms Safia Akhtar Khan for technical assistance.

\section{Disclosure}

The authors report no conflicts of interest in this work.

\section{References}

1. Terkeltaub RA. Colchicine update: 2008. Semin Arthritis Rheum. 2009; 38(6):411-419.

2. Sarı İ, Birlik M, Kasifoğlu T. Familial Mediterranean fever: an updated review. Eur J Rheumatol. 2014;1(1):21-33.

3. Ozcakar ZB, Kadioglu G, Siklar Z, et al. The effect of colchicine on physical growth in children with familial mediterranean fever. Eur J Pediatr. 2010;169(7):825-828.

4. Zadeh N, Getzug T, Grody WW. Diagnosis and management of familial Mediterranean fever: integrating medical genetics in a dedicated interdisciplinary clinic. Genet Med. 2011;13(3):263-269. 
5. Burns CM, Wortmann RL. Latest evidence on gout management: what the clinician needs to know. Ther Adv Chronic Dis. 2012;3(6): 271-286.

6. Terkeltaub RA. Gout. N Engl J Med. 2003;349(17):1647-1655.

7. Ben-Chetrit E, Levy M. Colchicine: 1998 update. Semin Arthritis Rheum. 1998;28(1):48-59.

8. Niel E, Scherrmann J-M. Colchicine today. Joint Bone Spine. 2006;73(6): 672-678.

9. Putterman C, Ben-Chetrit E, Caraco Y, Levy M. Colchicine intoxication: clinical pharmacology, risk factors, features, and management. Semin Arthritis Rheum. 1991;21(3):143-155.

10. Harris MD, Siegel LB, Alloway JA. Gout and hyperuricemia. Am Fam Physician. 1999;59(4):925-934.

11. Evans TI, Wheeler MT, Small RE, Breitbach SA, Sanders KM, Roberts WN. A comprehensive investigation of inpatient intravenous colchicine use shows more education is needed. J Rheumatol. 1996; 23(1):143-148.

12. Singh HP, Utreja P, Tiwary AK, Jain S. Elastic liposomal formulation for sustained delivery of colchicine: in vitro characterization and in vivo evaluation of anti-gout activity. AAPS J. 2009;11(1):54-64.

13. Singh HP, Tiwary AK, Jain S. Preparation and in vitro, in vivo characterization of elastic liposomes encapsulating cyclodextrin-colchicine complexes for topical delivery of colchicine. Yakugaku Zasshi. 2010; 130(3):397-407.

14. Jain S, Tiwary AK, Jain NK. PEGylated elastic liposomal formulation for lymphatic targeting of zidovudine. Curr Drug Deliv. 2008; 5(4):275-281.

15. Nava G, Piñón E, Mendoza L, Mendoza N, Quintanar D, Ganem A. Formulation and in vitro, ex vivo and in vivo evaluation of elastic liposomes for transdermal delivery of ketorolac tromethamine. Pharmaceutics. 2011;3(4):954-970.

16. Abdulbaqi IM, Darwis Y, Khan NA, Assi RA, Khan AA. Ethosomal nanocarriers: the impact of constituents and formulation techniques on ethosomal properties, in vivo studies, and clinical trials. Int $J$ Nanomedicine. 2016;11:2279-2304.

17. Song CK, Balakrishnan P, Shim CK, Chung SJ, Chong S, Kim DD. A novel vesicular carrier, transethosome, for enhanced skin delivery of voriconazole: characterization and in vitro/in vivo evaluation. Colloids Surf B Biointerfaces. 2012;92:299-304.

18. Ainbinder D, Touitou E. A new approach for skin tumor treatment: from delivery system characterization to in vivo evaluation. Drug Deliv Transl Res. 2011;1(1):53-65.

19. Ascenso A, Raposo S, Batista C, et al. Development, characterization, and skin delivery studies of related ultradeformable vesicles: transfersomes, ethosomes, and transethosomes. Int J Nanomedicine. 2015;10: 5837-5851.

20. Meng S, Chen Z, Yang L, et al. Enhanced transdermal bioavailability of testosterone propionate via surfactant-modified ethosomes. Int $J$ Nanomedicine. 2013;8:3051-3060.

21. Touitou E, Dayan N, Bergelson L, Godin B, Eliaz M. Ethosomes novel vesicular carriers for enhanced delivery: characterization and skin penetration properties. J Control Release. 2000;65(3):403-418.

22. Chourasia MK, Kang L, Chan SY. Nanosized ethosomes bearing ketoprofen for improved transdermal delivery. Results Pharma Sci. 2011;1(1):60-67.

23. Maheshwari RGS, Tekade RK, Sharma PA, et al. Ethosomes and ultradeformable liposomes for transdermal delivery of clotrimazole: a comparative assessment. Saudi Pharm J. 2012;20(2):161-170.

24. Abdulbaqi IM, Darwis Y, Khan NAK, Assi RA, Loh GOK. A simple (HPLC-UV) method for the quantification of colchicine in bulk and ethosomal gel nano-formulation and its validation. Int J Pharm Pharm Sci. 2017;9(7):72-78.

25. Zainol NA, Ming TS, Darwis Y. Development and characterization of cinnamon leaf oil nanocream for topicalapplication. Indian J Pharm Sci. 2015;77(4):422-433.

26. Meidan VM, Al-Khalili M, Michniak BB. Enhanced iontophoretic delivery of buspirone hydrochloride across human skin using chemical enhancers. Int J Pharm. 2003;264(1-2):73-83.
27. Malakar J, Sen SO, Nayak AK, Sen KK. Development and evaluation of microemulsions for transdermal delivery of insulin. ISRN Pharmaceutics. 2011;2011:780150.

28. Chen Y, Zhou L, Yuan L, Zhang Z-H, Liu X, Wu Q. Formulation, characterization, and evaluation of in vitro skin permeation and in vivo pharmacodynamics of surface-charged tripterine-loaded nanostructured lipid carriers. Int J Nanomedicine. 2012;7:3023-3033.

29. Akhtar N, Pathak K. Cavamax W7 composite ethosomal gel of clotrimazole for improved topical delivery: development and comparison with ethosomal gel. AAPS PharmSciTech. 2012;13(1):344-355.

30. Verma P, Pathak K. Nanosized ethanolic vesicles loaded with econazole nitrate for the treatment of deep fungal infections through topical gel formulation. Nanomedicine. 2012;8(4):489-496.

31. Hunter DG, Frisken BJ. Effect of extrusion pressure and lipid properties on the size and polydispersity of lipid vesicles. Biophys J. 1998; 74(6):2996-3002.

32. Colletier JP, Chaize B, Winterhalter M, Fournier D. Protein encapsulation in liposomes: efficiency depends on interactions between protein and phospholipid bilayer. BMC Biotechnol. 2002;2(9):1-8.

33. Song YK, Hyun SY, Kim HT, Kim CK, Oh JM. Transdermal delivery of low molecular weight heparin loaded in flexible liposomes with bioavailability enhancement: comparison with ethosomes. J Microencapsul. 2011;28(3):151-158.

34. Puri R, Jain S. Ethogel topical formulation for increasing the local bioavailability of 5-fluorouracil: a mechanistic study. Anticancer Drugs. 2012;23(9):923-934.

35. Limsuwan T, Amnuaikit T. Development of ethosomes containing mycophenolic acid. Procedia Chem. 2012;4:328-335.

36. Shamma RN, Elsayed I. Transfersomal lyophilized gel of buspirone $\mathrm{HCl}$ : formulation, evaluation and statistical optimization. J Liposome Res. 2013;23(3):244-254.

37. Ahad A, Aqil M, Kohli K, Sultana Y, Mujeeb M. Enhanced transdermal delivery of an anti-hypertensive agent via nanoethosomes: statistical optimization, characterization and pharmacokinetic assessment. Int J Pharm. 2013;443(1-2):26-38.

38. Pathak $P$, Nagarsenker $M$. Formulation and evaluation of lidocaine lipid nanosystems for dermal delivery. AAPS PharmSciTech. 2009;10(3): 985-992.

39. Lopez-Pinto JM, Gonzalez-Rodriguez ML, Rabasco AM. Effect of cholesterol and ethanol on dermal delivery from DPPC liposomes. Int J Pharm. 2005;298(1):1-12.

40. Zhaowu Z, Xiaoli W, Yangde Z, Nianfeng L. Preparation of matrine ethosome, its percutaneous permeation in vitro and anti-inflammatory activity in vivo in rats. J Liposome Res. 2009;19(2):155-162.

41. Liu X, Liu H, Liu J, et al. Preparation of a ligustrazine ethosome patch and its evaluation in vitro and in vivo. Int J Nanomedicine. 2011;6: 241-247.

42. Patel KK, Kumar P, Thakkar HP. Formulation of niosomal gel for enhanced transdermal lopinavir delivery and its comparative evaluation with ethosomal gel. AAPS PharmSciTech. 2012;13(4):1502-1510.

43. Paolino D, Lucania G, Mardente D, Alhaique F, Fresta M. Ethosomes for skin delivery of ammonium glycyrrhizinate: in vitro percutaneous permeation through human skin and in vivo anti-inflammatory activity on human volunteers. J Control Release. 2005;106(1-2): 99-110.

44. Bragagni M, Mennini N, Maestrelli F, Cirri M, Mura P. Comparative study of liposomes, transfersomes and ethosomes as carriers for improving topical delivery of celecoxib. Drug Deliv. 2012;19(7):354-361.

45. Lei W, Yu C, Lin H, Zhou X. Development of tacrolimus-loaded transfersomes for deeper skin penetration enhancement and therapeutic effect improvement in vivo. Asian J Pharm Sci. 2013;8(6): 336-345.

46. Liu D, Hu H, Lin Z, et al. Quercetin deformable liposome: preparation and efficacy against ultraviolet $B$ induced skin damages in vitro and in vivo. J Photochem Photobiol B. 2013;127:8-17.

47. Ogiso T, Yamaguchi T, Iwaki M, Tanino T, Miyake Y. Effect of positively and negatively charged liposomes on skin permeation of drugs. J Drug Target. 2001;9(1):49-59. 
48. Maestrelli F, Capasso G, Gonzalez-Rodriguez ML, Rabasco AM, Ghelardini C, Mura P. Effect of preparation technique on the properties and in vivo efficacy of benzocaine-loaded ethosomes. J Liposome Res. 2009;19(4):253-260.

49. Akar A, Bulent Tastan H, Erbil H, Arca E, Kurumlu Z, Gur AR. Efficacy and safety assessment of $0.5 \%$ and $1 \%$ colchicine cream in the treatment of actinic keratoses. J Dermatol Treat. 2001;12(4):199-203.

50. Kumari S, Pathak K. Cavamax W7 composite psoralen ethosomal gel versus cavamax W7 psoralen solid complex gel for topical delivery: a comparative evaluation. Int J Pharm Investig. 2013;3(4):171-182.

51. Razavi SMA, Karazhiyan H. Flow properties and thixotropy of selected hydrocolloids: experimental and modeling studies. Food Hydrocoll. 2009;23(3):908-912.
52. Mbah CC, Builders PF, Attama AA. Nanovesicular carriers as alternative drug delivery systems: ethosomes in focus. Expert Opin Drug Deliv. 2014;11(1):45-59.

53. Oh Y-K, Kim MY, Shin J-Y, et al. Skin permeation of retinol in Tween 20-based deformable liposomes: in-vitro evaluation in human skin and keratinocyte models. J Pharm Pharmacol. 2006;58(2):161-166.

54. Garg BJ, Garg NK, Beg S, Singh B, Katare OP. Nanosized ethosomesbased hydrogel formulations of methoxsalen for enhanced topical delivery against vitiligo: formulation optimization, in vitro evaluation and preclinical assessment. J Drug Target. 2016;24(3):233-246.

\section{Publish your work in this journal}

Drug Design, Development and Therapy is an international, peerreviewed open-access journal that spans the spectrum of drug design and development through to clinical applications. Clinical outcomes, patient safety, and programs for the development and effective, safe, and sustained use of medicines are the features of the journal, which has also been accepted for indexing on PubMed Central. The manuscript management system is completely online and includes a very quick and fair peer-review system, which is all easy to use. Visit http://www.dovepress.com/testimonials.php to read real quotes from published authors.

Submit your manuscript here: http://www.dovepress.com/drug-design-development-and-therapy-journal 